ISSN 0819-2642

ISBN 0734026269

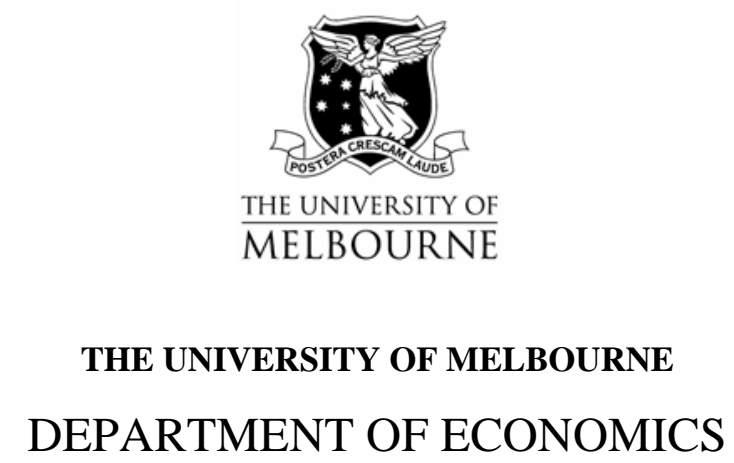

RESEARCH PAPER NUMBER 968

JULY 2006

The Cyclical Dynamics and Volatility of Australian Output and Employment

by

Robert Dixon

$\&$

David Shepherd

Department of Economics

The University of Melbourne Melbourne Victoria 3010

Australia. 


\title{
The Cyclical Dynamics and Volatility of Australian Output and Employment
}

\author{
David Shepherd \\ Robert Dixon \\ Imperial College London \\ University of Melbourne
}

\begin{abstract}
In this paper we examine the volatility of aggregate output and employment in Australia with the aid of a frequency filtering method (the Butterworth filter) that allows each time series to be decomposed into trend, cycle and noise components. This analysis is compared with more traditional methods based simply on the examination of first differences in the logs of the raw data using cointegration-VAR modelling. We show that the application of univariate AR and bivariate VECM methods to the data results in a detrended series which is dominated by noise rather than cyclical variation and gives break points which are not robust to alternative decomposition methods. Also, our conclusions challenge accepted wisdom in relation to output volatility in Australia which holds that there was a once and for all sustained reduction in output volatility in or around 1984. We do not find any convincing evidence for a sustained reduction in the cyclical volatility of the GDP (or employment) series at that time, but we do find evidence of a sustained reduction in the cyclical volatility of the GDP (and employment) series in 1993/4. We also find that there is a clear association between output volatility and employment volatility. We discuss the key features of the business cycle we have identified as well as some of the policy implications of our results.
\end{abstract}

JEL CODES E320 E370 E520 C220 C320

KEYWORDS Business cycles, volatility, inflation targeting, Australia

\section{Correspondence to:}

Robert Dixon, Department of Economics, The University of Melbourne, Victoria 3010, Tel: +61 38344 5352; Fax: +61 38344 6899. Email: r.dixon@unimelb.edu.au 


\section{Introduction}

In this paper we examine the volatility of aggregate output and employment in Australia with the aid of frequency filtering methods that allow each time series to be decomposed into trend, cycle and noise components, based on a prior consideration of macroeconomic theory and spectral analysis. This analysis is compared with more traditional methods based simply on the examination of first differences in the $\operatorname{logs}$ of the raw data using cointegration-VAR modelling. Our main contributions are as follows. First, we look not only at the volatility of output but also the volatility of employment and the relationship between the two. So far as we are aware this has not been attempted before. ${ }^{1}$ Second, we look at the volatility of both series using a filter (the Butterworth filter) which has not previously been applied to this data. At the very least, this will help to determine whether the results from growth rate models are robust with respect to alternative cycle-noise identification procedures. It may also help to provide additional insight into the cyclical dynamics of the series and especially the dates at which volatility changed.

An important feature of our research is that our conclusions challenge accepted wisdom in relation to output volatility in Australia. Previous work suggests that there was a once and for all sustained reduction in output volatility in or around 1984 (see for example Smith \& Summers, 2002, Cecchetti et al, 2005 and Taylor et al, 2005) and researchers have speculated on the causes of the decline in volatility using that date as the basis for their conjectures as to likely explanations. While it is tempting to accept this date as marking a watershed in the behavior of the macroeconomy (because it coincides with the deregulation of financial and other markets together with other changes in policy arrangements and settings commencing in 1983 ) it is a puzzling finding for many reasons. First, it is odd that the recession which commenced in 1990 is assigned to a less volatile period than is the recession which commenced in 1982, especially since most indicators suggest that the more recent recession was far more prolonged than the previous recession. Second, as will be seen below, the same techniques that

\footnotetext{
${ }^{1}$ While there have been numerous studies of aggregate employment in Australia, researchers have focused on the estimation of a neo-classical labour demand schedule and associated adjustment issues (see for example Russell \& Tease, 1991; Taplin \& Parameswaran, 1993; Stacey \& Downes, 1995; Phipps \& Sheen, 1995; Debelle \& Vickery, 1998; Dungey \& Pitchford, 1998; Downes \& Bernie, 1999; Lewis \& MacDonald, 2002; and Dixon et al, 2005) but have either not looked at volatility at all or, to the extent that they have, they have not looked at volatility using time series techniques.
} 
suggest a break in output volatility in 1984 indicate no break in employment volatility in that period, which raises the possibility that the date for the break in output volatility may not be correct. Third, intellectual curiosity would also leads us to wonder if the 1984 break date is not an artifact of the particular statistical techniques employed by previous researchers. Finally, it could be argued that the introduction of inflation targeting in the early 1990s could be expected to have had a discernible effect on output volatility and yet the papers referred to above do not discuss this (they imply that there was a change in 1984 and then no further change beyond that date). For this reason we are especially interested in assigning a date to the reduction in volatility and testing the robustness of the claim that there was a once and for all reduction in volatility in 1984 or thereabouts. A related issue is whether or not we can find any evidence that there was an increase in output volatility following the introduction of inflation targeting in 1993. ${ }^{2}$ Looking ahead to some of our conclusions, we do not find any convincing evidence for a sustained reduction in the cyclical volatility of the GDP (or employment) series in 1984 but we do find evidence of a sustained reduction in the cyclical volatility of the GDP (and employment) series in 1993/4. We also find that there is a clear association between output volatility and employment volatility.

As hinted at in our opening paragraph, we also hope to make a contribution to the method by which researchers approach the study of volatility. Much of the previous work on this topic (both in Australia and overseas) has been based on Cointegration-VAR-VECM methods, which generally suppose that the trends in the GDP and employment series can be represented as random walks with drift. Although these procedures are well-established, strictly speaking their applicability rests on the assumption that the trend component is properly represented as a random walk and that the cyclicality in each series is fully contained within the growth rate (the first difference of the logarithms of the variable) and, for cointegrated series, any associated equilibrium error-correction component. However, from the large literature on unit-root testing, we know that there is considerable uncertainty about the trend-generating process and that alternative approximations are potentially admissible, including segmented linear trends, fractionally integrated processes and mixed processes (see for example: Cochrane, 1988; Perron, 1990 \& 1997; Lumsdaine \& Papell, 1997; Bai \& Perron, 1998;

\footnotetext{
${ }^{2}$ Many researchers would argue that this would be the case, especially in the presence of supply shocks, see Cecchetti and Ehrmann (1999) for example.
} 
Leybourne, Mills \& Newbold, 1998; and Abadir \& Talmain, 2002). A worrying feature of this general class of models is that they typically yield the result that the business cycle is a very minor component of the series, with the bulk of the variation contained within the noise component. In view of this and especially given the uncertainty surrounding the trendgenerating process, it seems desirable to examine the volatility of aggregate output and employment with the aid of a trend (cycle) identification procedure (in our case, a Butterworth filter) that does not require the imposition of a unit root in the data-generating process. This allows us to assess whether the conclusions about cyclical dynamics (and especially the dates assigned to any breaks in volatility) from previous studies are robust with respect to alternative trend-cycle extraction procedures.

The paper is organized as follows. In the next section we outline the various econometric methods used to investigate the cycle and noise components of economic data. In section III we apply univariate AR and bivariate VECM methods to the data and examine the volatility of the cycle and noise components derived using these procedures. We show that the use of these procedures results in a detrended series which is dominated by noise rather than cyclical variation and gives break points which are not robust to alternative decomposition methods. Section IV looks at (Butterworth) frequency filtered cycle and noise. We find that the relative importance of the cycle and noise components is now reversed, in comparison with the results found earlier. While the filtered series confirms that there has been reduced noise volatility since the mid 1980s, it also suggests that there was a period of increased cyclical volatility during the 1980s and the early 1990s (with no break in cyclical volatility in 1984) but that this is followed by a return to a more normal cyclical volatility after 1994, of the kind the economy enjoyed before the 1980s. The final section concludes.

\section{Methodology and Statistical Considerations}

A common procedure when examining the time-path of a variable such as output or employment is to assume that the series is generated by a stochastic process that can be represented as the sum of trend $(\tau)$ and cyclical $(c)$ components, with additional noise $(e)$ or other irregular components:

$$
y_{\mathrm{t}}=\tau_{\mathrm{t}}+c_{\mathrm{t}}+e_{\mathrm{t}}
$$

If the objective of the investigation is to determine the cyclical dynamics of the series, it 
is necessary to detrend the series in some way. The problem is that the components of (1) are not directly observable and restrictions have to be placed on the data-generating process in order to obtain estimates of each of them. These restrictions can be purely statistical or they can be derived from economic theory. It is often assumed that the trend component can be represented as a random walk with drift, that the cyclical component can be represented as a stationary autoregressive process, and that the noise component can be regarded as a white noise process. For a univariate model, with the assumption of a random walk trend, the stationary cyclical component can be identified by the application of first differencing. The model for estimation purposes is then described by an AR process, such as

$$
\Delta y_{\mathrm{t}}=\mu+\theta_{1} \Delta y_{\mathrm{t}-1}+\ldots . .+\theta_{\mathrm{k}} \Delta y_{\mathrm{t}-\mathrm{k}}+e_{\mathrm{t}}
$$

In a bivariate or multivariate context, the procedure is essentially the same as the above, except that it is necessary to allow for the possibility that the series may share common trends and that the cyclical adjustment process may include an equilibrium error-correction component. If there is no common trend, the model for each series is the same as in (2). If there is a common trend, equation (2) needs to be supplemented with an error-correction term (EC) that represents the adjustment of the series to its long-run equilibrium (trend) level:

$$
\Delta y_{\mathrm{t}}=\mu+\theta_{1} \Delta y_{\mathrm{t}-1}+\ldots . .+\theta_{\mathrm{k}} \Delta y_{\mathrm{t}-\mathrm{k}}+\psi \mathrm{EC}_{\mathrm{t}-1}+e_{\mathrm{t}}
$$

If the series are measured in logarithms, equations (2) and (3) are models that describe the growth rate of the series in terms of a deterministic component (constant growth rate), a stationary cyclical component (and a stationary equilibrium adjustment term) with additive white noise.

A potential problem with models such as we have in equations (2) and (3) is that the identification of the cycle as an autoregressive process in the growth rate (and any associated equilibrium adjustment term) is valid only if the trend process can adequately be represented as a random walk. In contrast, if the trend is more properly described as a segmented linear trend or some other non-random walk process, the application of first-differencing effectively removes a significant part of the underlying cyclicality of the series and (incorrectly) identifies it as part of the variability of the trend. Expressed in the language of signal processing, the first differencing procedure acts as an inefficient high-pass filter that effectively pushes the identified cycle into the higher frequency ranges of the spectrum (see for example Llung \& Glad, 1994 and Baxter \& King, 1999). Insofar as the cyclical structure of the series is not 
properly identified, any corresponding analysis of the cyclical dynamics is potentially biased. ${ }^{3}$ In view of the potential bias arising from the application of an inappropriate trend-cycle-noise decomposition, it seems desirable to re-examine the cyclical component of the relevant series in the context of a model that allows for an alternative decomposition. This should also provide useful evidence about whether conclusions from previous studies are robust with respect to the detrending method.

Our approach is to separate the different components using spectral methods and frequency filtering in conjunction with the insights offered by economic theory. The starting point of the analysis is Parseval's relationship, described by equation (4) below. This shows that the total power (the total amount of variation) in a series is measured by its variance and, provided there exists a legitimate Fourier transform, this is equivalent to the sum of the power of the series across the frequency range $2 \pi$.

$$
\sum_{t=-\infty}^{\infty}|y(t)|^{2}=\frac{1}{2 \pi} \sum_{-\pi}^{\pi}\left|Y\left(e^{j \omega}\right)\right|^{2} d \omega
$$

where $\left|Y\left(e^{j \omega}\right)\right|$ is the Fourier transform and $\left|Y\left(e^{j \omega}\right)\right|^{2}$ is the power spectral density and $y(t)$ represents deviations from the mean of $Y(t)$.

Parseval's relationship provides the justification for switching between the time and frequency domains as appropriate and, with an appropriate filtering procedure, it is a straightforward matter to determine the series power which is contained within any frequency band. For non-stationary variables such as GDP and employment, the power of the series is dominated by low frequency (trend) components and any practical examination of higher frequency components, via the Fourier transform, requires some form of preliminary detrending with a high-pass filter. In the empirical business cycle literature, the Hodrick and Prescott (1997) filter has traditionally been used to extract cyclical information, although strictly speaking it acts only as a high-pass filter, with the filtered series containing a combination of both medium frequency (business cycle) components and higher frequency (noise) components. In contrast, the moving-average band-pass filter popularized by Baxter and King (1999) does in principle allow a more precise form of filtering, which can be used to

\footnotetext{
${ }^{3}$ A similar comment applies with respect to the numerous studies that aim to identify the structure and phases of the business cycle by examining the behaviour of GDP growth rates in the context of Markov-Switching models of the kind introduced by Hamilton (1989).
} 
separate variation at different frequencies as required.

Although the Baxter-King and Hodrick-Prescott filters are now in common use in economics, there are many other alternatives available. Our analysis is based on the application of a set of Butterworth filters that have been used extensively in signal processing applications. ${ }^{4}$ We use this filter in preference to the Baxter-King filter partly because of its well-established properties, including desirable cycle-identification features such as minimum rippling effects, and partly because existing algorithms allow flexible and transparent positioning of the required filter walls. ${ }^{5}$ The Butterworth filter can be represented as an ARMA filter of the form:

$$
y_{t}=\sum_{k=0}^{M} \alpha_{k} u_{t-k}+\sum_{k=1}^{N} \beta_{k} y_{t-k}
$$

Using this filter, with an appropriate choice of AR and MA parameters, the variation in the series can be isolated over any required frequency range. For the purpose of numerical estimation, however, it is more efficient to implement the filter in state-space form and the results presented later are based on this implementation. Detailed discussions of the filtering procedure and its properties can be found in numerous signal processing texts and economics journal articles and need not be repeated here. ${ }^{6}$ One point to note about this ARMA filter is that it is asymmetric and can therefore induce a degree of phase distortion in the filtered series. In practice this distortion can easily be eliminated by filtering the series first in a forwards and then in a backwards direction ${ }^{7}$. A more important problem is that an accurate picture of the cyclicality of the series is obtained, strictly speaking, only after the filter has reached its steady state, because the initial observations may be distorted by the presence of start-up transients in the system. The number of initial observations subject to potential transient distortion is equal to the length of the impulse response of the system, which rises with the order of the filter. ${ }^{8}$ To

\footnotetext{
${ }^{4}$ The Butterworth filter is one type of 'maximally flat magnitude' filter.

5 The computations reported in this paper were all undertaken in Matlab 5.2. The results from the high-pass and band-pass filtering procedures reported in the next section are derived from a Butterworth filter implemented in the FiltFilt function of the Matlab Signal Processing Toolbox.

${ }^{6}$ The properties of the Butterworth filter are discussed in Oppenheim and Willsky (1997). For recent discussions of this filter in an economics context, see Gomez, 2001; Harvey and Trimbur, 2003, and; Iacobucci and Noullez, 2005.

7 This is the implementation procedure used in the FiltFilt function referenced in a previous footnote.

${ }^{8}$ An equivalent problem exists in the application of moving average filters, such as the Baxter-King filter, in that the construction of the moving average uses up a range of observations at the beginning and end of the series and the number of lost observations rises with the order of the filter.
} 
make sure that the transients do not distort the results, we examined filtered data that both included and excluded the transient effects and in this particular application it would appear that the presence of the system transients do not significantly affect the results. ${ }^{9}$

The band-pass filter can be thought of as the combination of high-pass and low-pass filter walls and the most important matter for our purposes is that, in order to identify the trend, cycle and noise components for further analysis, it is necessary to determine an appropriate positioning of the walls. As is well known, there are a potentially infinite number of trendcycle-noise decompositions and an important initial matter is to determine which are relevant. Our approach to this problem is to apply the insights derived from economic theory in conjunction with prior spectral analysis of the detrended series. The starting point of the analysis is to recognize that the majority of theoretical treatments, and many policy applications, are based on the notion that trend output evolves according to the path of capital accumulation and total factor productivity and that these are driven by forces that are largely independent of the short-run cyclical variations. A further presumption, particularly in policy applications and empirical analysis is that business cycle variation can be thought of as occurring over cycles of between about 2-8 years, with variation below 2 years regarded essentially as noise and variations above 8 or so years regarded as closer to trend variation. While this information could be used on its own to position the band-pass filter walls, to ensure its applicability it is a straightforward matter to examine the power spectral density of the series, to determine whether there is in fact any concentration of power over the suggested business cycle range. Following this line of reasoning, the approach we adopt in this paper is to detrend the output and employment series, with the (high pass) filter wall set at the frequency implied by a maximum cycle length of 8 years duration (which in the present context is roughly equivalent to a frequency of 6 cycles per sample period). We then estimate the power spectral density of the detrended series and this information is then used to set the position of the second (low pass) wall of the filter. The band-pass filter extracts the cyclical component of the series. The trend in the series is extracted first by the first wall, used in the initial detrending procedure, and second wall is also used as the high pass wall that extracts the noise component.

\footnotetext{
${ }^{9}$ Our later empirical analysis is derived from a fourth order filter, which suggests that up to 30 observations (roughly the length of the impulse response) at the beginning of the series could be subject to potential distortion. However, the implementation of the Butterworth filter in the Matlab Signal Processing toolbox is particularly efficient at minimising the impact of the system transients.
} 
We then use the estimated components to examine the structure and dynamics (especially the volatility) and co-movement of the two series.

\section{Preliminary Statistical Analysis}

In this section we present an examination of the series using traditional AR and VECM methods. This provides both an overview of the series and a useful point of comparison for the later (and, in our view, more appropriate and powerful) analysis based on spectral methods and frequency filtering. The time series we examine are aggregate real GDP and aggregate employment in Australia over the period 1959:3 - 2005:4. ${ }^{10}$ Preliminary unit root tests indicate that both series can be characterised as I(1). Although the power of the ADF test to discriminate between alternative trend representations is limited, as noted earlier, we proceed initially on the assumption that the series (trends) can be characterised as random walks with drift. Plots of the first differences of the logarithms of the series are shown in Figure 1.

\section{[FIGURE 1 NEAR HERE]}

A visual inspection of the data suggests the possibility of a cyclical process in the employment series, although this is less clear for the output series. The output series appears to exhibit a reduction in volatility around the early/mid 1980s. As noted earlier various authors have identified a step reduction in the variance of output growth at 1984 (see for example Smith \& Summers, 2002; Cecchetti et al, 2005; Taylor et al, 2005). In the case of the employment growth series, there is no obvious reduction in volatility at this date, but we need to look at the formal modelling of the series to say anything of substance. The identification of a cyclical process is usually associated with the identification of an AR process. Results for this class of models are presented in this section of the paper. We begin by examining a univariate AR model for each series.

\section{(i) Univariate Modelling of the Series}

The univariate AR model results are shown below, with point estimates of the parameters $^{11}$ and the associated $95 \%$ confidence intervals. ${ }^{12}$

\footnotetext{
${ }^{10}$ Data is from the DX database. The aggregate (real) GDP series is VTEQ.AVCH_GDPA \$m 2003/04 sa. The aggregate (civilian) employment series is VTEQ.AN_NET '000 sa. Data downloaded on 4 May 2006.

${ }^{11} \mathrm{~A} *$ indicates significance at the $5 \%$ level.

${ }^{12}$ Preliminary testing suggests that an AR(1) model is sufficient for both series.
} 
Output growth: 1959:3-2005:4

$$
\Delta y_{\mathrm{t}}=0.009^{*}-0.06 \Delta y_{\mathrm{t}-1} \quad \mathrm{R}^{2}=0.004
$$

95\% confidence intervals: $\Delta y_{\mathrm{t}}=\left[\begin{array}{ll}0.007 & 0.011\end{array}\right]-\left[\begin{array}{ll}0.21 & -0.086\end{array}\right] \Delta y_{\mathrm{t}-1}$

The explanatory power of the model is negligible and there is no significant autoregressive cyclical feature. However, we need to bear in mind that there does appear to have been a break in the structure of the process around 1984. Estimates for the two sub-sample periods yield:

Output growth: 1959:3-1983:4

$$
\Delta y_{\mathrm{t}}=0.010^{*}-0.11 \Delta y_{\mathrm{t}-1} \quad \mathrm{R}^{2}=0.01
$$

95\% confidence intervals: $\Delta y_{\mathrm{t}}=\left[\begin{array}{ll}0.007 & 0.014\end{array}\right]-\left[\begin{array}{ll}0.32 & -0.087\end{array}\right] \Delta y_{\mathrm{t}-1}$

Output growth: 1984:1-2005:4

$$
\begin{aligned}
& \Delta y_{\mathrm{t}}=0.006^{*}+0.23^{*} \Delta y_{\mathrm{t}-1} \quad \mathrm{R}^{2}=0.05 \\
& 95 \% \text { confidence intervals: } \Delta y_{\mathrm{t}}=\left[\begin{array}{ll}
0.004 & 0.009
\end{array}\right]+\left[\begin{array}{ll}
0.02 & 0.44
\end{array}\right] \Delta y_{\mathrm{t}-1}
\end{aligned}
$$

The results for the two sub-periods point to a possible change in the dynamics of output growth as well as the variance after 1984:1, with a significant autoregressive (cyclical) feature emerging after 1984 in conjunction with the lower volatility. Note however that the explanatory power of the model is very low, with an $\mathrm{R}^{2}$ of only 0.01 in the first period and 0.05 in the second period. This means that, even though a cyclical process is identified, it is very weak and the bulk of the variation in the series is accounted for by the noise term (more on this shortly).

Employment growth: 1959:3-2005:4

$$
\Delta l_{\mathrm{t}}=0.003^{*}+0.39^{*} \Delta l_{\mathrm{t}-1} \quad \mathrm{R}^{2}=0.15
$$

95\% confidence intervals: $\Delta l_{\mathrm{t}}=\left[\begin{array}{ll}0.002 & 0.004\end{array}\right]+\left[\begin{array}{ll}0.26 & 0.53\end{array}\right] \Delta y_{\mathrm{t}-1}$

Although this equation has low explanatory power, there does appear to be a significant cyclical feature present. Unlike output growth, there is no obvious reduction in volatility in 1984 and this would appear to be confirmed by the sub-sample estimates reported below.

Employment growth: 1959:3-1983:4

$$
\Delta l_{\mathrm{t}}=0.002^{*}+0.51 * \Delta l_{\mathrm{t}-1} \quad \mathrm{R}^{2}=0.26
$$


95\% confidence intervals: $\Delta l_{\mathrm{t}}=\left[\begin{array}{ll}0.001 & 0.003\end{array}\right]+\left[\begin{array}{ll}0.34 & 0.68\end{array}\right] \Delta y_{\mathrm{t}-1}$

Employment growth: 1984:1-2005:4

$$
\Delta l_{\mathrm{t}}=0.004^{*}+0.27 * \Delta l_{\mathrm{t}-1} \quad \mathrm{R}^{2}=0.08
$$

95\% confidence intervals: $\Delta l_{\mathrm{t}}=\left[\begin{array}{ll}0.002 & 0.005\end{array}\right]+\left[\begin{array}{ll}0.07 & 0.48\end{array}\right] \Delta y_{\mathrm{t}-1}$

The overlapping confidence intervals across the two sub-periods suggest confirm that there is no significant change in the structure of the AR process before and after 1984. So there is no real justification in the case of this time series for employing a split sample estimate and the full sample result is the relevant one, indicating a significant AR(1) process explaining about $15 \%$ of the variation in employment growth.

\section{Volatility Analysis of Univariate Models}

We have already noted that previous work suggests a break in the volatility of output growth in 1984. Visual inspection of the output series appears to confirm this, but there is no obvious break at that date in the employment growth series. (The different behaviour of the volatility of the two series might be indicating that the use of first differences in the logarithms to measure volatility and to identify breaks in volatility might not be wise - more on this later.)

We investigate the possibility of breaks in the variances by examining the rolling volatilities of the series, which identify potential changes in their volatility structure. As a check on this procedure, we also apply the break detection algorithm developed by Andersson (1985), which uses Kalman Filter methods to identify the most likely break points in a time series. ${ }^{13}$ The break detection algorithm when applied to the rolling volatilities of the two growth rate series yields results consistent with the 1984 break point in the variance of GDP growth nominated in the papers mentioned above. In the case of employment growth, the results suggest possible changes in the variance around 1993.

We can get a visual picture of changes in the volatility structure of the series by examining their rolling variances. Figure 2 shows plots of the variances of output and employment growth, calculated over a rolling window of 20 quarters.

\section{[FIGURE 2 NEAR HERE]}

The turning points in the rolling variances give an indication of potential break points. 
The top panel of Figure 2 shows quite clearly the identified output volatility reduction around 1984. The plot of employment volatility is less clear cut, although it does point to possible volatility change around the 1993 date noted above. To determine whether these breaks are potentially significant, it is instructive to compare the variances for the sub-sample periods. This can be done by examining the variance ratios, $\operatorname{Var}\left(\Delta y_{\mathrm{t} 1}\right) / \operatorname{Var}\left(\Delta y_{\mathrm{t} 2}\right)$, where the subscripts 1 and 2 refer to the first and second sample periods. In order to determine the potential significance of any identified change in variance, we undertook a series of simulation experiments. Monte Carlo experiments based on 10,000 replications suggest that for sample lengths and breaks of the kind examined in this paper, at the conventional 5\% significance level, we would expect to see variance ratios (random differences in variances) in a range from 0.66 to 1.52 for a white noise process. For series with an autoregressive structure, the range of potential variation rises with the size of the autoregressive parameter. For an $\operatorname{AR}(1)$ process, $\Delta y_{\mathrm{t}}=\alpha \Delta y_{\mathrm{t}-1}+e_{\mathrm{t}}$, the simulations suggests ranges of the following order:

$$
\begin{aligned}
& \alpha=0.00 \rightarrow\left[\begin{array}{ll}
0.66 & 1.52
\end{array}\right] \\
& \alpha=0.25 \rightarrow\left[\begin{array}{ll}
0.64 & 1.56
\end{array}\right] \\
& \alpha=0.50 \rightarrow\left[\begin{array}{ll}
0.58 & 1.70
\end{array}\right] \\
& \alpha=0.75 \rightarrow\left[\begin{array}{ll}
0.46 & 2.05
\end{array}\right] \\
& \alpha=0.95 \rightarrow\left[\begin{array}{ll}
0.22 & 3.60
\end{array}\right]
\end{aligned}
$$

In the case of output growth, with the sample split at 1984:1, the variance ratio is 4.54 . Since this series is a near white noise process this is clearly significant, with the variance of the first period well over four times that of the second period. In contrast, the equivalent variance ratio for employment growth is 0.82 for a break set at 1984:1, which confirms the absence of a variance shift at that date. In the case of employment, the break detection algorithm and the rolling variance plots suggest that 1993 is a more likely date for any change in employment growth volatility and the variance ratio for this break is 1.71 . Note however, that the AR(1) model estimates suggest that employment growth follows an AR(1) process and that the AR parameter could be as high as 0.52 , which suggest that the 1.71 ratio is near the borderline of significance. We return to an examination of the volatility of the series later. For the moment we concentrate on co-movement.

\footnotetext{
${ }^{13}$ Details of the algorithm can be found in the Matlab System Identification toolbox.
} 


\section{(ii) Bivariate Analysis}

Assuming for the moment that the cyclical components are contained within the growth rates, a first assessment of the cyclical relationship of the series can be obtained from an examination of the cross-correlations. The correlations shown in Table 1 point to a weak but significant degree of co-movement, with the highest correlation $\left(\Delta y_{t}, \Delta l_{t+1}\right)$ indicating that changes in employment follow changes in output with a one-period lag.

\section{[TABLE 1 NEAR HERE]}

The correlation series provides only a cursory assessment of the cyclical relationship between the series. A more complete picture of the relationship can be obtained from a VAR analysis. In this case, the appropriate structure of the model depends on whether or not the series share a common stochastic trend. If there is no long-run cointegrating relationship, the dynamic behaviour of the series can be explained by a simple VAR model applied to the growth rates, as in equation (2). If the series are cointegrated, however, the model requires an additional error correction term, to capture the implied adjustment to long run equilibrium, in which case the appropriate model is equation (3).

Preliminary testing, using the Johansen and the Engle-Granger procedures suggests that the two series are cointegrated, so that error-correction model is appropriate. Having said this, it should be noted that, strictly speaking, the cointegration test assumes that the variances of the series are constant, whereas we have already seen that there is almost certainly a break in the variance of the GDP growth series around 1984:1 and that there is a possible break in the employment growth series in the early 90s. This means that the two series are not balanced over the whole sample and so there must be some doubt about the ability of the test to determine cointegration over the sample. In practice, this problem may not be sufficiently serious to affect the outcome of the tests, since they focus essentially on the mean of the series rather than the variance. For completeness however, to ensure the robustness of the cointegration tests, we tested for common trends and estimated the associated VAR models over the sub-periods 1959:3-83:4 and 1984:1-2005:4, as well as the full sample 1959:3-2005:4. The Johansen and Engle-Granger tests both suggested that the series are cointegrated over the sub-periods as well as the full sample. The cointegrating equation's results are shown below, with point estimates of the parameters and the associated $95 \%$ confidence intervals. 
Full Period Estimates: 1959:3-2005:4

Cointegrating Equation

$$
L_{\mathrm{t}}=2.58+0.54 Y_{\mathrm{t}}+e_{\mathrm{t}} \quad E C_{\mathrm{t}}=L_{\mathrm{t}}-2.58-0.54 Y_{\mathrm{t}}
$$

$\operatorname{VECM}^{14}$

$$
\begin{array}{ll}
\Delta l_{\mathrm{t}}=0.003^{*}-0.09^{*} E C_{\mathrm{t}-1}+0.35 \Delta l_{\mathrm{t}-1}+0.06^{*} \Delta y_{\mathrm{t}-1} & \mathrm{R}^{2}=0.25 \\
\Delta y_{\mathrm{t}}=0.008^{*}-0.03 E C_{\mathrm{t}-1}+0.43^{*} \Delta l_{\mathrm{t}-1}-0.12 \Delta y_{\mathrm{t}-1} & \mathrm{R}^{2}=0.05
\end{array}
$$

95\% confidence intervals

$$
\begin{aligned}
& \Delta l_{\mathrm{t}}=\left[\begin{array}{ll}
0.001 & 0.004
\end{array}\right]-\left[\begin{array}{ll}
0.14 & 0.04
\end{array}\right] E C_{\mathrm{t}-1}+\left[\begin{array}{ll}
-0.22 & 0.48
\end{array}\right] \Delta l_{\mathrm{t}-1}+\left[\begin{array}{ll}
0.01 & 0.13
\end{array}\right] \Delta y_{\mathrm{t}-1} \\
& \Delta y_{\mathrm{t}}=\left[\begin{array}{ll}
0.005 & 0.010
\end{array}\right]-\left[\begin{array}{ll}
0.14 & -0.08
\end{array} E C_{\mathrm{t}-1}+\left[\begin{array}{ll}
0.13 & 0.74
\end{array}\right] \Delta l_{\mathrm{t}-1}-\left[\begin{array}{ll}
0.28 & -0.03
\end{array}\right] \Delta y_{\mathrm{t}-1}\right.
\end{aligned}
$$

First Period Estimates: 1959:3-1983:4

Cointegrating Equation

$$
L_{\mathrm{t}}=2.75+0.52 Y_{\mathrm{t}}+e_{\mathrm{t}} \quad E C_{\mathrm{t}}=L_{\mathrm{t}}-2.75-0.52 Y_{\mathrm{t}}
$$

\section{VECM}

$$
\begin{array}{ll}
\Delta l_{\mathrm{t}}=0.002^{*}-0.11^{*} E C_{\mathrm{t}-1}+0.48^{*} \Delta l_{\mathrm{t}-1}+0.03 \Delta y_{\mathrm{t}-1} & \mathrm{R}^{2}=0.34 \\
\Delta y_{\mathrm{t}}=0.007^{*}+0.04 E C_{\mathrm{t}-1}+0.79^{*} \Delta l_{\mathrm{t}-1}-0.20 \Delta y_{\mathrm{t}-1} & \mathrm{R}^{2}=0.09
\end{array}
$$

95\% confidence intervals

$$
\begin{aligned}
& \Delta l_{\mathrm{t}}=\left[\begin{array}{ll}
0.001 & 0.003
\end{array}\right]-\left[\begin{array}{ll}
0.19 & 0.03
\end{array}\right] E C_{\mathrm{t}-1}+\left[\begin{array}{ll}
0.31 & 0.66
\end{array}\right] \Delta l_{\mathrm{t}-1}+\left[\begin{array}{ll}
-0.04 & 0.10
\end{array}\right] \Delta y_{\mathrm{t}-1} \\
& \Delta y_{\mathrm{t}}=\left[\begin{array}{ll}
0.003 & 0.010
\end{array}\right]+\left[\begin{array}{ll}
-0.21 & 0.29
\end{array}\right] E C_{\mathrm{t}-1}+\left[\begin{array}{ll}
0.23 & 1.34
\end{array}\right] \Delta l_{\mathrm{t}-1}-\left[\begin{array}{ll}
-0.21 & 0.29
\end{array}\right] \Delta y_{\mathrm{t}-1}
\end{aligned}
$$

Second Period Estimates: 1984:1 -2005:4

Cointegrating Equation

$$
L_{\mathrm{t}}=2.73+0.53 Y_{\mathrm{t}}+e_{\mathrm{t}} \quad E C_{\mathrm{t}}=L_{\mathrm{t}}-2.73-0.53 Y_{\mathrm{t}}
$$

\footnotetext{
${ }^{14}$ Again, a * indicates significant at the 5\% level.
} 
VECM

$$
\begin{array}{ll}
\Delta l_{\mathrm{t}}=0.003^{*}-0.12^{*} E C_{\mathrm{t}-1}+0.11 \Delta l_{\mathrm{t}-1}+0.13 \Delta y_{\mathrm{t}-1} & \mathrm{R}^{2}=0.23 \\
\Delta y_{\mathrm{t}}=0.007^{*}-0.08 E C_{\mathrm{t}-1}+0.01 \Delta l_{\mathrm{t}-1}+0.17 \Delta y_{\mathrm{t}-1} & \mathrm{R}^{2}=0.09
\end{array}
$$

$95 \%$ confidence intervals

$$
\begin{aligned}
& \Delta l_{\mathrm{t}}=\left[\begin{array}{ll}
0.001 & 0.005
\end{array}\right]-\left[\begin{array}{ll}
0.19 & 0.05
\end{array}\right] E C_{\mathrm{t}-1}+\left[\begin{array}{ll}
-0.10 & 0.32
\end{array}\right] \Delta l_{\mathrm{t}-1}+\left[\begin{array}{ll}
-0.05 & 0.30
\end{array}\right] \Delta y_{\mathrm{t}-1} \\
& \Delta y_{\mathrm{t}}=\left[\begin{array}{ll}
0.004 & 0.010
\end{array}\right]-\left[\begin{array}{ll}
0.17 & -0.01
\end{array}\right] E C_{\mathrm{t}-1}+\left[\begin{array}{ll}
-0.26 & 0.28
\end{array}\right] \Delta l_{\mathrm{t}-1}+\left[\begin{array}{ll}
-0.05 & 0.39
\end{array}\right] \Delta y_{\mathrm{t}-1}
\end{aligned}
$$

Apart from the results of the cointegration tests, noted earlier (which indicate that common trends are present across each sample period), the parameters of the three cointegrating equations are very similar, strongly indicating that the cointegrating relationship is stable and that a common trend can be identified across the sample periods. Looking at the VECM model estimates, the results for the three periods are again consistent, indicating that the error correction parameter is significant in the employment equation, but insignificant in the output equation. This carries the implication that output is the long-run forcing variable in the system, in the sense that it is short-run (cyclical) changes in employment rather than output that bring about the return to long-run equilibrium.

Plots of the cycles and the residual noise in output and employment growth implied by the VECM model, are shown in Figures 3 and 4. It is striking that the plots of the noise component in Figures 3 and 4 are so closely related to the variation in the raw growth rates plotted in Figure 1. Clearly, even the VECM model is generating a detrended series which is dominated by noise rather than cyclical variation

\section{[FIGURES 3 AND 4 NEAR HERE]}

\section{Volatility Analysis of the Bivariate Models}

It is again instructive to look briefly at the volatility structures. We do this by examining the rolling variances of the cyclical and noise components. Figure 5 shows the rolling variances of the output cycle and noise components. Note here that we have already seen that the explanatory power of the VECM model is very low, which means that the identified cycle is very weak in comparison with the noise component and the cycle-generating parameters (the $\mathrm{AR}$ and error-correction parameters in the output equation) are actually statistically 
insignificant. Nevertheless, it is worth looking at because it is a first pass at the identification of the properties of the output cycle.

\section{[FIGURE 5 NEAR HERE]}

The output cycle appears to exhibit an increase in volatility around the mid-1970s, with a downturn in volatility in the period 1993-1995. In contrast, the noise component exhibits the move to lower volatility around 1984. Given that the bulk of the variation in output growth is accounted for by the noise component, this is very much to be expected. The variance ratios with break points at 1984:1 are 0.84 for the cycle components and 3.91 for the noise component, which confirms that there is a reduction in the noise volatility at 1984:1, but no equivalent reduction in cycle volatility at that date. The absence of an identified break at 1984:1 for the output cycle is not surprising, since the rolling variance plot suggests that any breaks are likely to have occurred in the 1990s rather than 1984. We come back to this point in Section IV when we examine the results for the frequency filtered models.

The equivalent plots for the employment cycle and noise components of the VECM are shown in Figure 6. The employment cycle exhibits similar features to the output cycle (shown in Figure 5), with a possible fall in volatility in the early 90s. In this case, the variance ratios for the pre and post $1984: 1$ periods are 0.82 for the cycle component and 0.74 for the noise component, which confirms the absence of any significant break at that date for both the cycle and noise components. Again, we look more closely at the volatility structure of the employment components in section IV of the paper, in the context of the frequency-filtered models.

\section{[FIGURE 6 NEAR HERE]}

The cointegration-VECM results across the whole of our sample period could be refined further by introducing additional relevant explanatory variables, such as the real wage, and incorporating more sophisticated measures of the independent variables, such as hours worked rather than employment. It is also possible to introduce potential asymmetries in the adjustment process (as in Dixon et al, 2005) or regime shifts in the AR or VAR model (as in Taylor et al, 2005). Despite these possibilities, a worrying feature of this general class of models is that they effectively suppose that the business cycle is a very minor component of the series, with the bulk of the variation contained within the noise component of the model. In the present case, although the VECM estimates appear to be robust, and the relationships are stable over the 
sample period, the explanatory power of the equations, judged by the $\mathrm{R}^{2}$ statistics, is relatively low. For the full sample estimates, only $5 \%$ of the variance of output growth and $25 \%$ of the variance of employment growth is explained by the model, even with the equilibrium adjustment term included. Furthermore, quite apart from the low explanatory power of the models, a further problem is that the basic assumption of a random walk trend is questionable, given the low power of trend tests to distinguish between different alternatives, including segmented linear trends, mixed processes and fractionally integrated processes. In view of these problems, it seems desirable to look at the output and employment dynamics with an alternative cycle representation.

\section{Spectral Analysis and Frequency Filtering}

In this section we examine the trend, cycle and noise components in aggregate GDP and employment derived from a non-parametric analysis based on a combination of spectral methods and frequency filtering applied to the (log) levels of the GDP and employment series rather than their first differences (i.e. the growth rates). The analysis presented below is based on the methodology outlined earlier in Section II.

We have already noted that the first differencing procedure acts as an inefficient filtering procedure which emphasizes the higher frequency ranges of the spectrum. These higher frequency ranges are usually associated with the noise component of the model, rather than the cycle, and so one of the consequences of using the first difference filter is that it may generate a detrended series which is dominated by noise rather than cyclical variation. This (at least in part) explains why growth rate models of the cycle tend to have a relatively low explanatory power. In the case of the output series in particular, we have already seen that less than $10 \%$ of the variance of the series is explained by the autoregressive and error correction components that are used to represent the cycle, which implies that the dominant process is white noise rather than a cyclical process. This point is illustrated in Figure 7, which plots the power spectral density (PSD) of output growth and employment growth, together with the PSD of two typical white noise processes, generated by taking random draws from the standard normal distribution to generate a series with a sample length equal to the employment and output growth series. The basic idea is that a white noise process exhibits power (randomly) across all of the non-zero (stationary) ranges of the spectrum, so that, while the PSD may 
exhibit peaks at different frequencies, they should be 'evenly' spread across the whole of the frequency spectrum. ${ }^{15}$ In contrast, when a cyclical process is present in the series, such as the cycle that might be generated by an AR process, we would expect to see a concentration of peaks at the lower frequency end of the spectrum. On the plots, the lower frequency (business cycle) range is the range towards the origin (between about 6 and 23 cycles per period) while the higher frequency (noise) range lies across the $24-92$ cycles per period range. ${ }^{16}$

[FIGURE 7 NEAR HERE]

We see in Figure 7 that the PSD of the output growth series exhibits a pattern which is typical of a white noise process, with no pronounced concentration of power over any particular frequency range. This mirrors the time domain estimates of the VECM model, which show a very weak or non-existent AR process in output growth. In contrast, the PSD of the employment growth series shows a pronounced peak over the business cycle range, mirroring the time domain estimates, which show a significant AR process at work.

Returning to our analysis of the levels of the series, rather than the growth rates, the starting point is to remove the trend component with an initial high-pass filter. The filter acts as a preliminary detrending procedure and yields a series which embodies only the cycle and noise components. The power spectral density of the detrended series is then examined, to ensure that there is a significant concentration of power in the business cycle frequency ranges. ${ }^{17}$ The initial high-pass filter is a fourth-order Butterworth filter designed to remove the low frequency variation in the series, defined in the present context as cycles of more than 8 years duration. ${ }^{18}$ Plots of the detrended series for output and employment are shown in Figure 8. In contrast to plots of the growth rates of the variables (see for example Figure 1 above), a visual inspection of the series suggests that a strong cyclical process is present in both series. ${ }^{19}$

\footnotetext{
${ }^{15}$ The term 'white noise' is based on an analogy with white light, which is made up of equal contributions across the entire colour spectrum.

${ }^{16}$ Since at least 2 observations are needed to observe any variation, the maximum number of cycles per sample period (the highest frequency) is equal to half the length of the sample, which is approximately 92 cycles per period in the present instance. This highest (maximum) frequency is the Nyquist frequency.

${ }^{17}$ The preliminary examination of the PSD is important because it ensures that the detrended series does contain a concentration of power within the relevant range and that the second-stage band pass filter can therefore legitimately be applied. This matter is discussed further in Shepherd (2005).

${ }^{18}$ To avoid any distortion arising from possible transient effects, the results in this section are based on an analysis of the filtered data with the first 30 observations removed. The results are similar when the initial observations are included. It should be noted also that we experimented with different frequency bands, which allowed the cycle length to be extended to up to 10 years. Again, the results were broadly similar to those reported here.

${ }^{19}$ Given the interest shown in dating Australian GDP turning points it is worthwhile for us to report the
} 


\section{[FIGURE 8 NEAR HERE]}

One objective of the initial detrending is to determine whether there is a concentration of power over business cycle frequencies. The frequency structure of the variation in each series is given in Figure 9, which show PSD plots of the two detrended series. The plots suggest that, for both series, the bulk of the power is concentrated in a frequency range associated with cycle lengths of between 8 and 2 years duration (between 6 and 23 cycles per sample period). ${ }^{20}$

\section{[FIGURE 9 NEAR HERE]}

\section{Filtered cycle and noise components}

The concentrations of power suggested by the spectral estimates of the detrended series are very much in line with the ranges suggested by macroeconomic analysis and so we used the identified $8-2$ year cycle period as the band-width for a Butterworth band-pass filter designed to extract the cyclical variation of the series. (The remaining variation in the series is then regarded as being equivalent to higher-frequency noise.) Plots of the (filtered) cycles are shown in Figure 10 and plots of the (filtered) noise in Figure 11. We will deal with each in turn.

\section{[FIGURE 10 NEAR HERE]}

Table 2 shows the cross-correlations between the output and employment cycles $\left(l_{C \mathrm{t}}\right.$ and $\left.y_{C t}\right)$. The contemporaneous correlation between the two is 0.67 and in this case the highest correlation is at 0.81 , when employment lags output by 2 quarters. This suggests a slightly longer delay in the impact of changes in output on employment than was implied by the growth rate model (a 2-quarter rather than a than a 1-quarter delay).

\section{[TABLE 2 NEAR HERE]}

The filtering procedure not only gives us a more focused picture of the nature of the

contraction and expansion phases for our detrended output series. They are: expansion phase - 1961:1, contraction 1961:2 - 1962:4, expansion 1963:1 - 1965:3, contraction 1965:4 - 1969:3, expansion 1969:4 1972:2, contraction 1972:3 - 1972:4, expansion 1973:1 - 1974:1, contraction 1974:2 - 1975:4, , expansion 1976:1 - 1977:2, contraction 1977:3 - 1979:3, expansion 1979:4 - 1982:2, contraction 1982:3 - 1984:4, expansion 1985:1 - 1986:1, contraction 1986:2 - 1987:3, expansion 1987:4 - 1990:4, contraction 1991:1 - 1993:4, expansion 1994:1 - 1996:1, contraction 1996:2 - 1998:2, expansion 1998:3 - 2000:3, contraction 2000:4 2002:1, expansion 2002:2 - 2002:3, contraction 2002:4 - 2003:3, expansion 2003:4 - 2004:3, contraction 2004:4 - 2005:1, expansion 2005:2 -.

${ }^{20}$ The higher frequency boundary of 2 years is a proper spectral estimate, whereas the lower frequency boundary 
cyclical component in the series but, in addition, it provides useful insight into the nature of the noise component and the potential deficiencies of the first difference filter.

\section{[FIGURE 11 NEAR HERE]}

As already mentioned, plots of the noise components are shown in Figure 11. Although, as expected, there is no significant correlation between the two noise series it is instructive to look at the correlation between the noise component of each series and the corresponding growth rates examined in the previous section. In the case of output, the contemporaneous correlation between the growth rate of the series and the filtered noise component is highly significant at 0.68 and for employment growth there is a significant contemporaneous correlation of 0.50 between the growth rate and the filtered employment noise component. This confirms what was said earlier, namely that the first differencing procedure effectively generates a series in which the true cyclical process is heavily dominated by the noise component.

It is important to note that the relative importance of the cycle and noise components is now reversed, in comparison with the growth rate model. The earlier results for the growth rate models suggest that the noise components account for somewhere between $90 \%$ and $95 \%$ of the variance of output growth and somewhere between $75 \%$ and $85 \%$ of the variance of employment growth, which means that the cyclical components account for no more than $10 \%$ and $25 \%$ respectively of the variance of the growth rates. In contrast, the filtered cycle in output accounts for $94 \%$ of the variance of the detrended series, with the remaining $6 \%$ accounted for by noise. In the case of employment the filtered cycle accounts for $74 \%$ of the variance of the detrended series, with the remaining $26 \%$ attributable to the noise component.

\section{Main Features of the (Filtered) Cycle}

Given the interest shown in dating and analyzing key features of the Australian business cycle (see Boehm \& Summers, 1999; Bodman \& Crosby, 2002; Cashin \& Ouliaris, 2004, and Di Venuto \& Layton, 2005 for recent examples) it is worthwhile examining some of the key features of the filtered cycle shown in Figure 10. Specifically, we report the chronology for the contraction and expansion phases for our output cycle and examine key characteristics of 
expansions and contractions.

Table 3 gives four pieces of information for expansion and contraction phases separately: the dates during which the economy was in that phase; the number of quarters involved in each phase; the amplitude of each phase (defined as the sum of the calculated values of $c$ from beginning to end of that phase) and the quarterly amplitude (defined as the mean of the calculated values of $c$ in each quarter from the beginning to end of that phase). The values of $c$ represent the proportionate deviations (positive or negative) from potential output. The contrast between the recessions of the early 80 s and the early 90 s is quite marked. ${ }^{21}$

\section{[TABLE 3 NEAR HERE]}

Over the period (working only with completed phases the first cycle starts in 1961:1 and the last cycle ends in 2003:2) there were 10 contractions and 9 expansions. The total length of time the economy spent in a contraction phase and in an expansion phase were the same, 85 quarters (but notice that this does not include the two incomplete expansion phases at the beginning and end of our sample period). The average duration of a contraction was 8.5 quarters and the average duration of an expansion was 9.5 quarters. The average (quarterly) amplitude of a contraction was -0.0095 and the average (quarterly) amplitude of an expansion was 0.0080 , so there appears to be some asymmetry with the speed of contractions being on average close to $20 \%$ faster than expansions. Treating the mean figures as absolute values, there appears to be no significant difference in the mean values for the expansion and contraction phases. The $95 \%$ confidence interval for the difference in the means is $[-0.0033$ 0.0011] which encompasses zero.

\section{The Volatility of the Cycle and Noise Components of the Two Series}

We complete our analysis of the filtered series by considering what the results suggest for the volatility structure of the cycle and noise components of output and employment. Looking first at the cyclical components, the plots in Figure 10 are suggestive of an increase in the variance of both the employment and output cycles around 1980/81 and a subsequent reduction in the volatility of both series around $1993 / 4 .{ }^{22}$ We can now investigate this more

\footnotetext{
${ }^{21}$ And all the more so as we are looking here not at the detrended series but only at the cyclical component of the detrended series.

${ }^{22}$ These results are robust with respect to variations in the length of the defined cycle in that the duration of the business cycle can be stretched to 10 years rather than 8 years duration without significantly affecting the results.
} 
closely using the methods developed earlier.

Plots of the rolling variances of the cycles are shown in Figure 12. These plots suggest that there was a significant change in the variance of both cycles around 1980/81 and in 1993/94. Andersson's (1985) segmentation algorithm mentioned earlier also suggests that 1980/81 and 1993/94 are the most likely break points in the series. Following this pointer, we divided the series up into three periods, dated at pre-1981, 1981-1993 and post 1993. Denoting these periods as 1, 2 and 3, we then examined the variance of the first period relative to the second (Var1/Var2), the variance of the third period relative to the second (Var3/Var2) and the variance of the first period relative to the third (Var1/Var2). The variance ratio statistics are: $\operatorname{Var} 1 / \operatorname{Var} 2=0.196, \operatorname{Var} 3 / \operatorname{Var} 2=0.192$ and $\operatorname{Var} 1 / \operatorname{Var} 3=1.02$. The variances of the first and third periods are clearly very similar and they are both significantly lower than the cycle variance in the middle period, with period 2 exhibiting a variance which is over five times that of periods 1 and 2. As an additional check, we examined the variances periods using Levene's (1960) test for variance constancy. The test indicates that, at the 5\% significance level, the null of no change in variance is rejected for $\operatorname{Var}(1) / \operatorname{Var}(2)$ and $\operatorname{Var}(3) / \operatorname{Var}(2)$, but not rejected for $\operatorname{Var}(1) / \operatorname{Var}(2)$. These results strongly suggest that the period over the 1980s and the early 1990s was one in which business cycle fluctuations were much more pronounced than they were in later and earlier periods. Similar results are obtained if the middle period is defined over 19801994. Experimentation with other break dates suggest that the break in the volatility of the employment cycle tends to lag the break in the volatility of the output cycle by 1 or 2 quarters, as the cyclical correlations noted earlier would imply. In contrast, if we split the sample at 1984:1, there is no significant break identified in either the output or employment cycles, with the variance ratio of the output cycle being only 1.52, which is not statistically significant according to the monte carlo simulation results noted earlier. This emphasizes the point made earlier that the volatility reduction in 1984 identified in the growth rate model should not be regarded as a reduction in cyclical volatility.

\section{[FIGURE 12 NEAR HERE]}

Turning to the noise component, the rolling volatility plots, shown in Figure 13, suggest that there has been no break in employment noise at any time during our sample period but that there was a shift to lower volatility in output noise around 1984. However, given that the noise component is only $5 \%$ of detrended output, this is not enough to generate a one-step reduction 
in the volatility of detrended output. The variance of detrended output is dominated by the behaviour of the cycle component, which follows the switching pattern noted above ie lowerhigher-lower, with the switches at 1980/81 and 1993/4.

[FIGURE 13 NEAR HERE]

With a break defined at 1984:1, the variance ratio for output noise, measured for the period before the break relative to the period after the break, is 5.39, indicating that the noise volatility of the pre-1984 period is over 5 times that of the post-1984 period. With the 1984:1 split imposed on the employment series, the equivalent variance ratio is 0.91 , which indicates no significant change in the employment noise volatility. Experimentation with other possible break dates revealed no significant change in the structure of the noise volatility of the employment series. The reduction in noise volatility thus appears to be confined to output.

\section{Output Growth and Volatility}

We have identified three phases of cyclical volatility (and the reader will recall that in all three periods cyclical volatility dominates any noise volatility). The phases we have identified are: 1 (pre-1981) - a period of low volatility; 2 (1981-1993) - a period of high volatility, and; 3 (1994-2005) - another period of low volatility. In this subsection we enquire into the relationship between output growth rate and volatility.

The reader will recall that our non-parametric approach identifies the components of the growth rate in each period as frequency domain components, which are low frequency (trend), middle frequency (business cycle) and high frequency (noise) components). In this model the trend is variable and so trend growth can change over time. Viewed from this perspective, when we examine the growth rate of output, measured as changes in the logarithm of GDP, it is important to bear in mind that it contains changes in the levels of all the components. Using the notation of equation (1) above, the growth rate can therefore be decomposed as:

$$
\Delta y=\Delta \tau+\Delta c+\Delta e
$$

In other words, the growth rate $(\Delta y)$ contains underlying changes in the trend growth of potential output and transitory changes due to cyclical fluctuations around trend and noise where $c$ and $e$ are (zero) mean reverting processes. Given this, we should focus our attention on whether or not there is an association between the growth rate of the trend in each of our sub-periods with the degree of volatility in each of those sub-periods. 
Figure 14 shows two series, one is the observed growth rate of output in each period, the other (the smoother of the two lines) is the trend growth rate in each period. The difference between the observed growth rate of output in any period and the trend growth rate is (obviously) accounted for by changes in the cyclical and noise components, which by construction have a zero mean.

\section{[FIGURE 14 NEAR HERE]}

So the question to be addressed is whether or not there is any link between the volatility phases identified above and the means of the trend growth rate in each of the phases. Tests for differences in mean growth rates over the three periods (i.e. comparing 1 with 2, 2 with 3 and 1 with 3 suggest that, while there is no significant difference between mean trend growth in period 1 and period 3, mean trend growth in both period 1 and period 3 are higher than the mean trend growth in period $2 .^{23}$ The $95 \%$ confidence intervals for the differences in trend growth between the periods are: $[1,2] \rightarrow\left[\begin{array}{lll}0.0003 & 0.0022\end{array}\right],[2,3] \rightarrow[0.0005 \quad 0.0021]$, and $[1,3] \rightarrow[-0.0009 \quad 0.0009]$. The difference between the mean in period 2 and the common mean for periods 1 and 3 is not large, but it is statistically significant at the 5\% level. We conclude that trend growth was slightly lower during the higher volatility phase and so there is some evidence to support the view that high volatility is associated with low growth and vice versa (but notice that we are not asserting anything about the direction of causation). ${ }^{24}$

\section{$V$ Summary and Conclusions}

In this paper we examined the nature and sources of volatility in the Australian economy, using both an autoregressive model applied to the growth rate series and a set of nonparametric filtering procedures applied to the (logarithms of the) levels of aggregate GDP and employment. The main objectives were to determine when the reduction in output (especially) and employment volatility occurred and also to see if the conclusions drawn from autoregressive models of output growth are robust with respect to variations in the trend-cycle decomposition algorithm.

We have shown that the application of univariate AR and bivariate VECM methods to

\footnotetext{
${ }^{23}$ The means of the growth rates of the trend for each period are: $1=0.0087,2=0.0074$ and $3=0.0087$.

${ }^{24}$ Much of the literature has tended to focus on reasons why high volatility might result in slower growth arguing that high volatility can result in wasted human capital (Martin \& Rogers, 1997; 2000 and Blackburn \& Pelloni, 2005) or can deter investment and the implementation of newer technologies (Pindyck, 1991, and Ramey \&
} 
the data results in a detrended series which is dominated by noise rather than cyclical variation and gives break points which are not robust to alternative decomposition methods. Essentially the problems with these approaches are: (a) they effectively assume that the trend contains almost all of the variation in the series (the trend and the series are almost identical) so that there is little for a model of the business cycle to explain; (b) the first difference procedure is actually an inefficient form of detrending, which emphasises high frequency noise components - this largely explains the poor explanatory power of most growth rate models - they are really trying to model noise; (c) the power of statistical tests to distinguish between alternative trendgenerating processes is very limited.

When we apply a (Butterworth) frequency filtered procedure we find that the detrended series is dominated by cyclical rather than noise variation. Also, while the filtered series confirms that there has been a reduction in noise volatility since the mid 1980s, it also suggests that there was a period of increased cyclical volatility during the 1980s and the early 1990s (with no break in cyclical volatility in 1984) and that this is followed by a return to a more normal cyclical volatility after 1994, of the kind the economy enjoyed before the 1980s. We also found some evidence to support the view that high volatility is associated with low growth and vice versa and that there appears to be no significant difference in amplitude of business cycle contractions compared with expansions.

We have also shown that the growth rate models yield very little information about comovement. (For example, there is a significant co-movement between output growth and employment growth, but it is very weak and the cyclical association isn't very clear, particularly in terms of the separation of cycle and noise relationships.) In contrast, the results for the frequency filter analysis not only suggest a much more important cyclical element in the employment and output series but also point clearly to a strong link between the two cycles, with output appearing to drive employment.

Turning to the implications of our findings for current Australian economic policy, our most important conclusion relates to an issue foreshadowed in our introduction, namely - is there any evidence that there was an increase in output volatility following the introduction of inflation targeting in 1993? We answer this in the negative (indeed, we find a marked reduction

Ramey, 1991). 
in volatility in 1993/4). Our findings are consistent with ${ }^{25}$ the proposition that 'flexible' inflation targeting of the kind we have in Australia either lowers (rather than raises) the volatility of output or at least that the trade off between inflation variability and output volatility is more benign than critics of inflation targeting suggest. ${ }^{26}$ Further, in so far as output variations appear in the Central Bank's loss function (or if the Central Bank is using a de facto Taylor rule - see De Brouwer \& Gilbert, 2005) then, as Ball (1999) and others have shown, any reduction in output volatility must cet. par. be associated with lower interest rate volatility.

In addition, by examining the persistence of the output cycle we are able to comment on the appropriateness of inflation compared to price level targeting on the part of the central bank, the choice between the two being crucially dependent on whether or not the degree of persistence (the $\mathrm{AR}(1)$ parameter for output is greater or less than 0.5 , with price level targeting being favoured if the degree of persistence exceeds 0.5 (Svensson, $1997 \&$ 1999a \& b, Dittmar et al, 1999, and Cecchetti \& Kim, 2004). We find that our de-trended filtered series is an AR(1) process over the whole sample period with an AR(1) parameter of 0.63 with $95 \%$ confidence intervals of [0.52 0.74], so there is some evidence in favour of price level targeting over (rate of) inflation targeting. ${ }^{27}$

\footnotetext{
${ }^{25}$ But this by no means 'proves' that the proposition is true. For example, Ball \& Sheridan (2005), amongst others, argue that countries without inflation targeting also experienced declines in output volatility in the 1990s and so it is difficult to argue that it was targeting per se that resulted in the decline. On the other hand, Ceccheti, FloresLagunes \& Krause (2002) and Kent, Smith \& Holloway (2005) find evidence that a move to a stricter monetary policy regime is associated with a reduction in output volatility, even after allowing for a decline in global shocks. ${ }^{26}$ This has been argued by Svensson (1997) and Debelle (1999), amongst others. RBA Governor Macfarlane has said that Bank's approach to monetary policy is "essentially medium to long-term in nature" $(2000, \mathrm{p} 1)$ and that it aims "to provide the conditions which maximise the length of economic expansions" (ibid, p4). Interestingly, Kutter (2004) found that shocks to inflation are less persistent among inflation targeters than among non-targeters and argues that this is because, "with inflation expectations more firmly anchored by the inflation target, there is less of a tendency for inflation shocks to propagate through wage- and price-setting behaviour" (p 23).

${ }^{27}$ If we exclude the period since the start of inflation targeting in 1993(2) - see Dixon \& Lim (2004) and Stevens, $(1999,2003)$ for discussion of the date at which inflation targeting commenced - the AR(1) parameter is 0.65 with $95 \%$ confidence intervals of [0.52 0.78],
} 


\section{REFERENCES}

Abadir, K. M. and Talmain, G. (2002), 'Aggregation, Persistence and Volatility in a Macroeconomic Model', Review of Economic Studies, 69, 749-79.

Andersson, P. (1985), 'Adaptive Forgetting in Recursive Identification through Multiple Models', International Journal of Control, 42, 1175-193.

Bai, J. and Perron, P. (1998), 'Estimating and Testing Linear Models with Multiple Change Points', Econometrica, 66, 47-78.

Ball, L. (1999), 'Efficient Rules for Monetary Policy', International Finance, 2, 63-83.

Ball, L. and Sheridan, N. (2005), 'Does Inflation Targeting Matter?', in B. Bernanke and M. Woodford (eds), The Inflation-Targeting Debate, University of Chicago Press, Chicago, 249-76.

Baxter, M. and King, R. G. (1999), 'Measuring Business Cycles: Approximate Band-Pass Filters for Economic Time Series', Review of Economics and Statistics, 81, 575-93.

Blackburn, K. and Pelloni, A. (2005), 'Growth, Cycles, and Stabilization Policy', Oxford Economic Papers, 57, 262-82

Bodman, P. and Crosby, M. (2002), 'The Australian Business Cycle: Joe Palooka or Dead Cat Bounce?', Australian Economic Papers, 41, 191-207.

Boehm, E. and Summers, P. (1999), 'Analysing and Forecasting Business Cycles with the Aid of Economic Indicators', International Journal of Management Reviews, 1, 245-77.

Cashin, P. and Ouliaris, S. (2004), 'Key Features of Australian Business Cycles', Australian Economic Papers, 43, 39-58.

Cecchetti, S. and Ehrmann, M. (1999) Does Inflation Targeting Increase Output Volatility?, NBER Working Paper 7426, National Bureau of Economic Research Cambridge, Mass.

Cecchetti, S. and Kim, J. (2004), 'Inflation Targeting, Price Level Targeting, and Output Variability' in B. Bernanke and M. Woodford (eds), The Inflation Targeting Debate, University of Chicago Press, Chicago, 173-95.

Cecchetti, S., Flores-Lagunes, A. and Krause, S. (2005), 'Assessing the Sources of Changes in the Volatility of Real Growth', in C. Kent and D. Norman (eds), The Changing Nature of the Business Cycle, Proceedings of a Conference, Reserve Bank of Australia, Sydney, $115-38$. 
Cochrane, J. (1988), 'How Big is the Random Walk in GDP?' Journal of Political Economy, 96, 893-920.

De Brouwer, G. and Gilbert, J. (2005), 'Monetary Policy Reaction Functions in Australia', Economic Record, 81, 124-34.

Debelle, G. (1999), Inflation Targeting and Output Stabilisation, Research Discussion Paper 1999-08, Reserve Bank of Australia, Sydney.

Debelle, G. and Vickery, J. (1998), 'The Macroeconomics of Australian Unemployment', in G. Debelle and J. Borland (eds), Unemployment and the Australian Labour Market, Proceedings of a Conference, Reserve Bank of Australia, Sydney, 235-65.

Dittmar, R., Gavin, W. and Kydland, F. (2000), 'The Inflation-Output Variability Tradeoff and Price-Level Targets', The Federal Reserve Bank of St. Louis Review, 82, 21-30.

Di Venuto, N. and Layton, A. (2005), 'Do the Phases of the Business Cycle Die of Old Age?', Australian Economic Papers, 44, 290-305.

Dixon, R. and Lim G. C. (2004), 'Underlying Inflation in Australia: Are the Existing Measures Satisfactory?', Economic Record, 80, 373-86.

Dixon, R., Freebairn, J. and Lim G. C. (2005), 'An Employment Equation for Australia', Economic Record, 81, 204-14.

Downes, P. and Bernie, K. (1999), The Macroeconomics of Unemployment in the Treasury Macroeconomic (TRYM) Model, TYRM Related Paper No. 20, Commonwealth Treasury, Canberra.

Dungey, M. and Pitchford, J. (1998), 'Prospects for Output and Employment Growth with Steady Inflation', in G. Debelle and J. Borland (eds), Unemployment and the Australian Labour Market, Proceedings of a Conference, Reserve Bank of Australia, Sydney, 20824.

Gomez, V. (2001), 'The use of Butterworth filters for trend and cycle estimation in economic time series,' Journal of Business \& Economic Statistics, 19, 365-373.

Gruen, D. and Stevens, G. (2000), 'Australian Macroeconomic Performance and Policies in the 1990s', in D. Gruen and S. Shrestha (eds), The Australian Economy in the 1990s, Proceedings of a Conference, Reserve Bank of Australia, Sydney, 32-72.

Hamilton, J. (1989), 'A New Approach to the Economic Analysis of Non-stationary Time Series and the Business Cycle', Econometrica, 57, 357-84. 
Harvey, A. and Trimbur, T. (2003) 'General Model-Based Filters For Extracting Cycles And Trends In Economic Time Series', Review of Economics and Statistics, 85, 244-55.

Hodrick, R. and Prescott, E. (1997), 'Post-War Business Cycles: An Empirical Investigation', Journal of Money Credit and Banking, 29, 1-16.

Iacobucci, A. and Noullez, A. (2005), 'A Frequency Selective Filter for Short-Length Time Series', Computational Economics, 25, 75-102.

Kent, C., Smith, K. and Holloway, J. (2005), 'Declining Output Volatility: What Role for Structural Change?' in C. Kent and D. Norman (eds), The Changing Nature of the Business Cycle, Proceedings of a Conference, Reserve Bank of Australia, Sydney, 14680.

Kutter, K. (2004), 'A Snapshot of Inflation Targeting in its Adolescence', in C. Kent and S. Guttmann (eds), The Future of Inflation Targeting, Proceedings of a Conference, Reserve Bank of Australia, Sydney, 6-42.

Levene, H. (1960), 'Robust Test for Equality of Variance', in I. Olkin (ed), Contributions to Probability and Statistics, Stanford University Press, Palo alto California, 278-92.

Lewis, P. and MacDonald, G. (2002), 'The Elasticity of Demand for Labour in Australia', Economic Record, 78, 18-30.

Leybourne, S., Mills, T. and Newbold, P. (1998), 'Spurious Rejections by Dickey-Fuller Tests in the Presence of a Break Under the Null', Journal of Econometrics, 87, 191-203.

Llung, L. and Glad, T. (1994). Modeling of Dynamic Systems, Prentice-Hall

Lumsdaine, R. and Papell, D. (1997), 'Multiple Trends and the Unit Root Hypothesis', Review of Economics and Statistics, 79, 212-18.

Macfarlane, I. (1999), 'Six Years of Inflation Targeting, Reserve Bank of Australia Bulletin, May, 46-61.

Macfarlane, I. (2000), 'A Medium-term Perspective on Monetary Policy', Reserve Bank of Australia Bulletin, September, 1-5.

Martin, P. and Rogers, C. (1997), 'Stabilization Policy, Learning by Doing, and Economic Growth', Oxford Economic Papers, 49, 152-66.

Martin, P. and Rogers, C. (2000), 'Long-term Growth and Short-term Economic Instability', European Economic Review, 44, 359-381. 
Oppenheim, A. and Willsky, A. (1997). Signals and Systems, second edition, Prentice-Hall International

Perron, P. (1990), 'Testing for a Unit Root in a Time Series with a Changing Mean', Journal of Business and Economic Statistics, 8, pp 152-62.

Perron, P. (1997), 'Further Evidence on Breaking Trend Functions in Macroeconomic Variables', Journal of Econometrics, 80, 355-85.

Phipps, A. and Sheen, J. (1995), 'Macroeconomic Policy and Employment Growth in Australia', Australian Economic Review, 28, 86-104.

Pindyck, R. (1991), 'Irreversibility, Uncertainty, and Investment', Journal of Economic Literature, 29, 1110-48.

Ramey, V. and Ramey, G. (1991), Technology Commitment and the Cost of Economic Fluctuations, Working Paper 3755, National Bureau of Economic Research, Cambridge, Mass.

Russell, B. and Tease, W. (1991), 'Employment, Output and Real Wages', Economic Record, 67, 34-45.

Shepherd, D. (2005), The Use of Band-Pass Filters in Economics: Choices, Pitfalls and Estimation Strategy, Imperial College London. Mimeo

Simon, J. (2001), The Decline in Australian Output Volatility, Research Discussion Paper 2001-01, Reserve Bank of Australia, Sydney.

Smith, P. and Summers, P. (2002), Regime Switches in GDP Growth and Volatility: Some International Evidence and Implications for Modelling Business Cycles, Working Paper 2002n21, Melbourne Institute of Applied Economic and Social Research, The University of Melbourne, Melbourne.

Stacey, G. and Downes, P. (1995), Wage Determination and the Labour Market in the Treasury Macroeconomic (TRYM) Model, TYRM Related Paper No. 13, Commonwealth Treasury, Canberra.

Stevens, G. (1999), 'Six Years of Inflation Targeting', Reserve Bank of Australia Bulletin, May, 46-61.

Stevens, G. (2003), 'Inflation Targeting: A Decade of Australian Experience', Reserve Bank of Australia Bulletin, April, 17-29.

Svensson, L. (1997), 'Inflation Forecast Targeting: Implementing and monitoring inflation 
targets', European Economic Review, 41, 1111-46.

Svensson, L. (1999a), 'Price-Level Targeting versus Inflation Targeting: A Free Lunch?', Journal of Money, Credit and Banking, 31, 277-95.

Svensson, L. (1999b), 'Inflation Targeting as a Monetary Policy Rule', Journal of Monetary Economics, 43, 607-54.

Taplin, B. and Parameswaran, P. (1993), Employment, Investment, Inflation and Productivity: Decisions by the Firm, TYRM Related Paper No. 3, Commonwealth Treasury, Canberra.

Taylor, A., Shepherd, D. and Duncan, S. (2005), 'The Structure of the Australian Growth Process: A Bayesian Model Selection View of Markov Switching', Economic Modelling, 22, 628-45.

Truman, E. (2003), Inflation Targeting, Institute for International Economics, Washington. 


\section{APPENDIX I: The De-trended Series}

In this appendix we look at the volatility structure of the detrended series itself. Plots of the rolling variances of the detrended series, which identify potential turning points in the variance, are shown in Figure A1.

\section{[FIGURE A1 NEAR HERE]}

These plots suggest that there was a significant change in the variance of both cycles around 1980/81 and 1993/94. Following this pointer, we divided the series up into three periods, dated at pre-1981, 1981-1993 and post 1993. Again, denoting theses periods as 1, 2 and 3, we then examined the variance of the first period relative to the second ( $\operatorname{Var} 1 / \operatorname{Var} 2)$, the variance of the third period relative to the second (Var3/Var2) and the variance of the first period relative to the third (Var1/Var2). The variance ratio statistics for output are: Var1/Var2 $=0.19, \operatorname{Var} 3 / \operatorname{Var} 2=0.10$ and $\operatorname{Var} 1 / \operatorname{Var} 3=2.08$. The equivalent variance ratios for employment for the same three periods are: $\operatorname{Var} 1 / \operatorname{Var} 2=0.23 ; \operatorname{Var} 3 / \operatorname{Var} 2=0.31$, and; $\operatorname{Var} 1 / \operatorname{Var} 3=0.73$. The employment variance ratios confirm the picture for the employment cycle analysis as given in the text surrounding Figure 12 in the main text. Periods 1 and 3 have significantly lower volatility than period 2 and there is no significant difference in the volatilities of periods 1 and 3 .

The results for detrended output clearly indicate that the variance of the middle period is much higher than the first and third periods. But also $\operatorname{Var}(1)$ appears to be higher than $\operatorname{Var}(3)$, with a ratio of 2.08. This compares to a variance ratio of 1.02 for the equivalent cycle variance ratio. The ratio of $\operatorname{var}(3) / \operatorname{var}(2)$ at 0.10 is also much lower than the equivalent 0.192 recorded for the cycle ratio for 3,2. The explanation of this has two elements. First, according to our simulation experiments, the difference between $\operatorname{Var}(1)$ and $\operatorname{Var}(3)$ for detrended output is probably not a significant difference, because this is clearly a process with a high autoregressive element and the figure of 2.08 is either not significant or is on the test borderline for processes with high AR parameters. The second point to note is that the detrended series contains both noise and cycle variation and we know that there was a significant reduction in noise variance around 1984, which contributes to a reduction in variance in the last period, compared to the first period. In other words, the separate cycle and noise ratios give a cleaner picture of what is going on. Note this also illustrates why frequency filtering is in many ways 
superior to simple detrending, which is what is shown here and is what we would get from a high-pass filter such as the Hodrick-Prescott filter, which is popular with many researchers.

\section{APPENDIX II. Additional AR Modeling of the De-trended Series}

In this Appendix we use AR modelling to identify the cycle and noise structure from the detrended series. As will be seen, the AR(1) model does quite a good job in identifying the cycle, where it is judged in comparison to the frequency filtering.

Consider first an AR model of the detrended output series. Preliminary testing indicates that an AR(1) model is appropriate. Denoting the detrended output series as Yd, the estimated model for the full sample (ie including any transient effects) is: ${ }^{28,29}$

$$
\mathrm{Yd}_{\mathrm{t}}=0.65 \mathrm{Yd}_{\mathrm{t}-1}+\mathrm{u}_{\mathrm{t}} \quad \mathrm{R}^{2}=0.42 \text { with } 95 \% \text { confidence interval }\left[\begin{array}{ll}
0.53 & 0.76
\end{array}\right]
$$

If we apply an AR(1) to employment, for the full sample we get: ${ }^{30}$

$$
\mathrm{Ld}_{\mathrm{t}}=0.87 \mathrm{Ld}_{\mathrm{t}-1}+\mathrm{u}_{\mathrm{t}} \quad \mathrm{R}^{2}=0.76 \text { with } 95 \% \text { confidence interval }\left[\begin{array}{ll}
0.80 & 0.94
\end{array}\right]
$$

These results suggests that there is a high degree of persistence and thus cyclicality in both series, as measured by the AR parameters, but it is significantly stronger in the employment series (suggesting that shocks have a more persistent - longer lasting - impact on employment than on output. ${ }^{31}$

In this context, we can perhaps get a better view of the persistence by looking at a bivariate $\operatorname{VAR}(1)$ model rather than $\mathrm{AR}(1)$. For the full sample, the model estimates for aggregate output are:

$$
\mathrm{Yd}_{\mathrm{t}}=0.63 \mathrm{Yd}_{\mathrm{t}-1}+0.04 \mathrm{Ld}_{\mathrm{t}-1} \mathrm{u}_{\mathrm{t}} \quad \mathrm{R}^{2}=0.42 \mathrm{CI}=\left[\begin{array}{ll}
0.50 & 0.76
\end{array}\right]\left[\begin{array}{ll}
-0.14 & 0.22
\end{array}\right]
$$

and so we would conclude that lagged $\mathrm{L}$ isn't significant in explaining $\mathrm{Y}$, while for employment we find:

$$
\mathrm{Ld}_{\mathrm{t}}=0.15 \mathrm{Yd}_{\mathrm{t}-1}+0.76 \mathrm{Ld}_{\mathrm{t}-1} \mathrm{u}_{\mathrm{t}} \quad \mathrm{R}^{2}=0.79 \quad \mathrm{CI}=\left[\begin{array}{ll}
0.09 & 0.21
\end{array}\right] \quad\left[\begin{array}{lll}
0.68 & 0.84
\end{array}\right]
$$

and so we would conclude that lagged $\mathrm{Y}$ is significant in explaining L. ${ }^{32}$ Note also that the

\footnotetext{
${ }^{28}$ The detrended series has zero mean by construction.

${ }^{29}$ The result is almost identical if we drop the first 30 observations, to exclude possible transient effects. The $\mathrm{AR}(1)$ parameter is 0.64 with $\mathrm{CI}=\left[\begin{array}{ll}0.52 & 0.76\end{array}\right]$ and $\mathrm{R}^{2}=0.41$.

${ }^{30}$ If we exclude the transients, the result is 0.88 for the AR parameter with $\mathrm{CI}=\left[\begin{array}{ll}0.80 & 0.95\end{array}\right]$ and $\mathrm{R} 2=0.77$.

${ }^{31}$ Note this mirrors the result for the growth rate models, which show that employment growth has the bigger AR parameter and higher $\mathrm{R}^{2}$ than output growth.

${ }^{32}$ With transients excluded the results are similar:
} 
inclusion of $\mathrm{Y}$ as well as $\mathrm{L}$ brings down the AR parameter on lagged $\mathrm{L}$ from 0.87 in the $\mathrm{AR}(1)$ model to 0.76 in the VAR(1) model.

Set out below are plots of the AR(1) models of detrended output and employment. They show that the AR(1) model does quite a good job of identifying cycle and noise components, in so far as the implied cycle and noise components of the model are similar to those derived from the frequency filtering. This is in a sense to be expected.

How similar is the cycle in detrended output to the frequency filtered output cycle? Set out below is a plot for the two series side by side ie the cycle implied by an AR(1) fitted to detrended output and the cycle component extracted by the Butterworth filter as in the main paper. The correlation between the two series is 0.78 , which suggests that they are not bad alternatives.

\section{[FIGURE A2 NEAR HERE]}

How similar is the cycle in detrended employment to the frequency filtered employment cycle? Set out below is a plot for the two employment series side by side ie the cycle implied by an $\operatorname{AR}(1)$ fitted to detrended output and the cycle component extracted by the Butterworth filter as in the main paper. The correlation between the two series is 0.89 , which again suggests that they are not bad alternatives.

\section{[FIGURE A3 NEAR HERE]}

At one level the results here show that the frequency filtering procedure is not so very different to AR modelling, which is not surprising in view of the following: (a) The time and frequency domain analyses are mirrors of each other (i.e. everything that can be identified in the frequency domain can in principle be identified in the time domain and vice versa) and it is possible to switch back and forth between them as necessary. In practice, the choice between them in any particular context depends on which is more transparent and easier to understand. In the context of cycle analysis, frequency domain is generally easier to understand. (b) The frequency filter is an ARMA filter and so we would expect the results to have some similarity to an AR model. Again, the frequency choice is simply more transparent

The results indicate that a simple AR(1) model is quite good at cycle identification. However, the important point is that it needs to be applied to data that has retained the cyclical component. First differencing effectively destroys the cyclical component and hence there is little or nothing for the $\mathrm{AR}(1)$ model to explain when it is applied to growth rates. 


\section{FIGURES}

FIGURE 1

\section{Australian Output and Employment Growth}

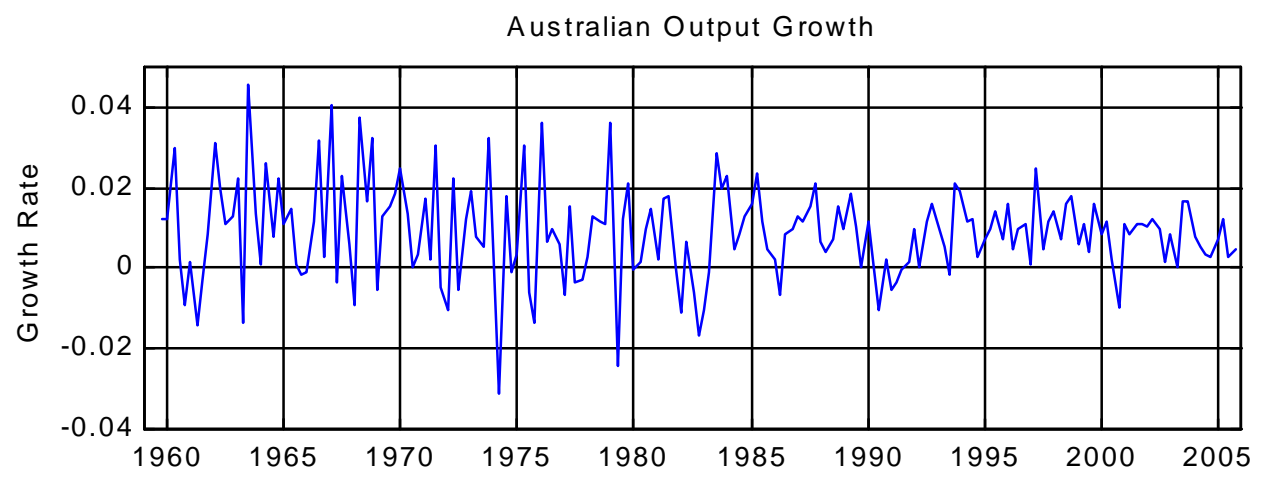

Australian Employment Growth

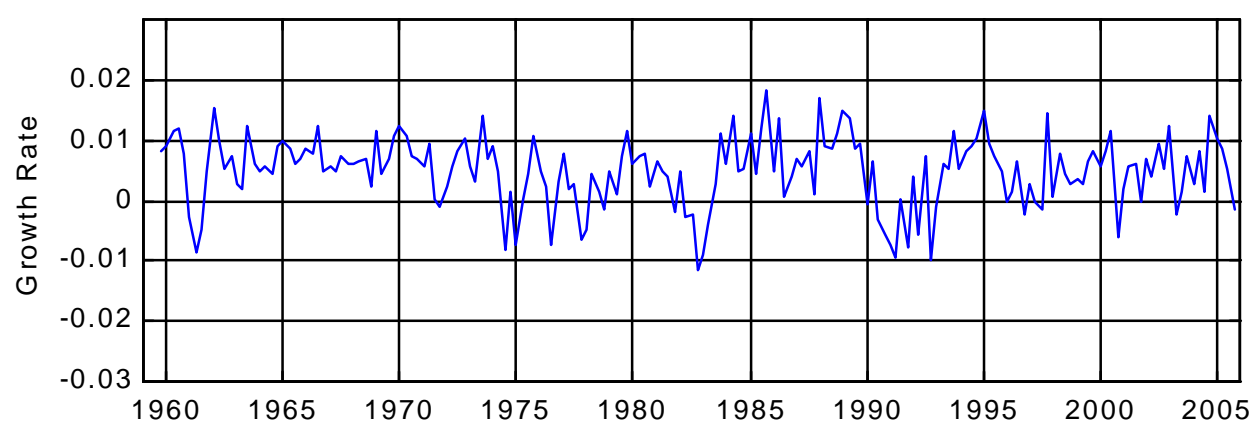


FIGURE 2

Rolling Variances of Output and Employment Growth
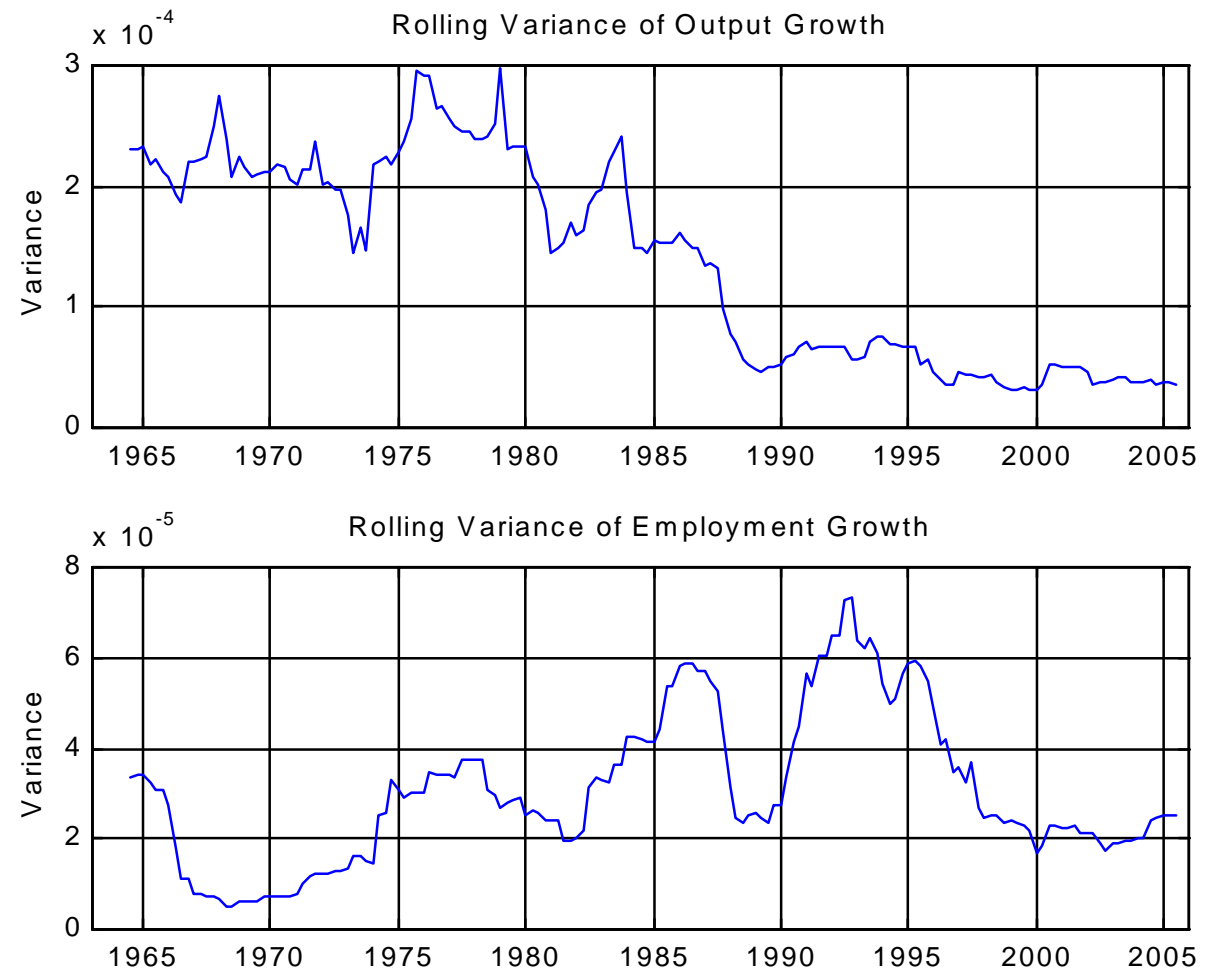
FIGURE 3

VECM Output Cycle and Noise
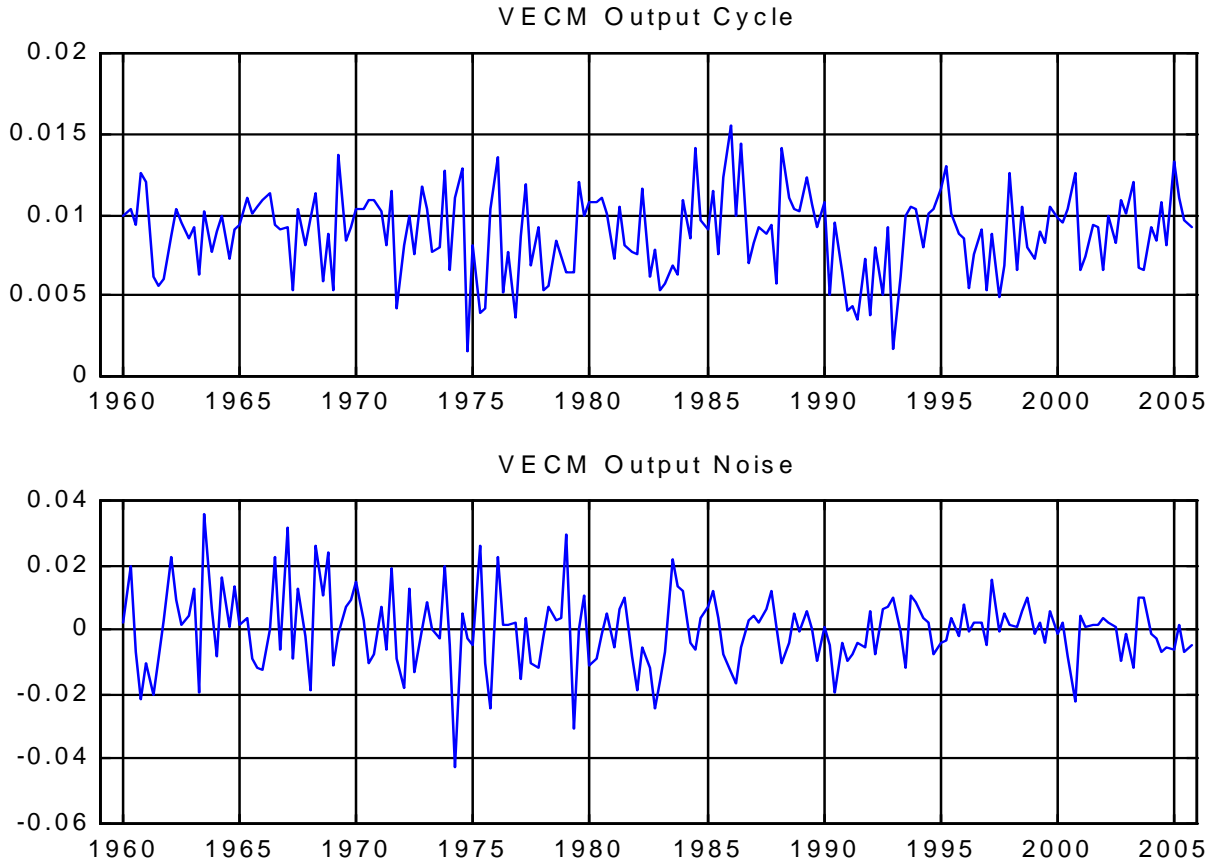

FIGURE 4

VECM Employment Cycle and Noise

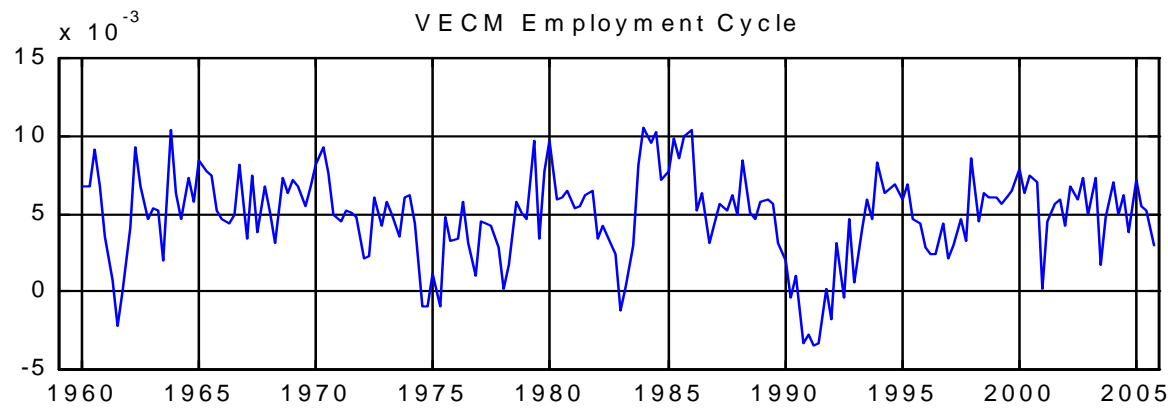

VECM Em ploym ent $\mathrm{N}$ oise

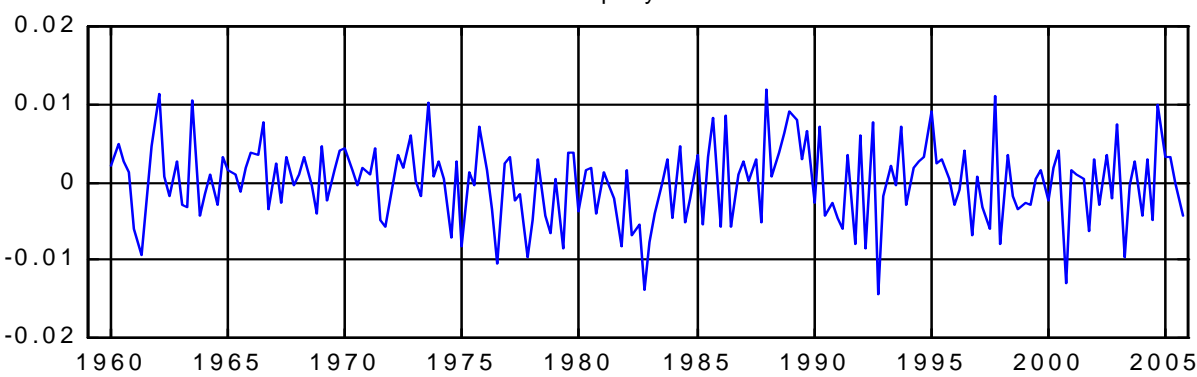


FIGURE 5

Rolling Variances of VECM Output Cycle and Noise Components

FIGURE 6

Rolling Variances of VECM Employment Cycle and Noise Components
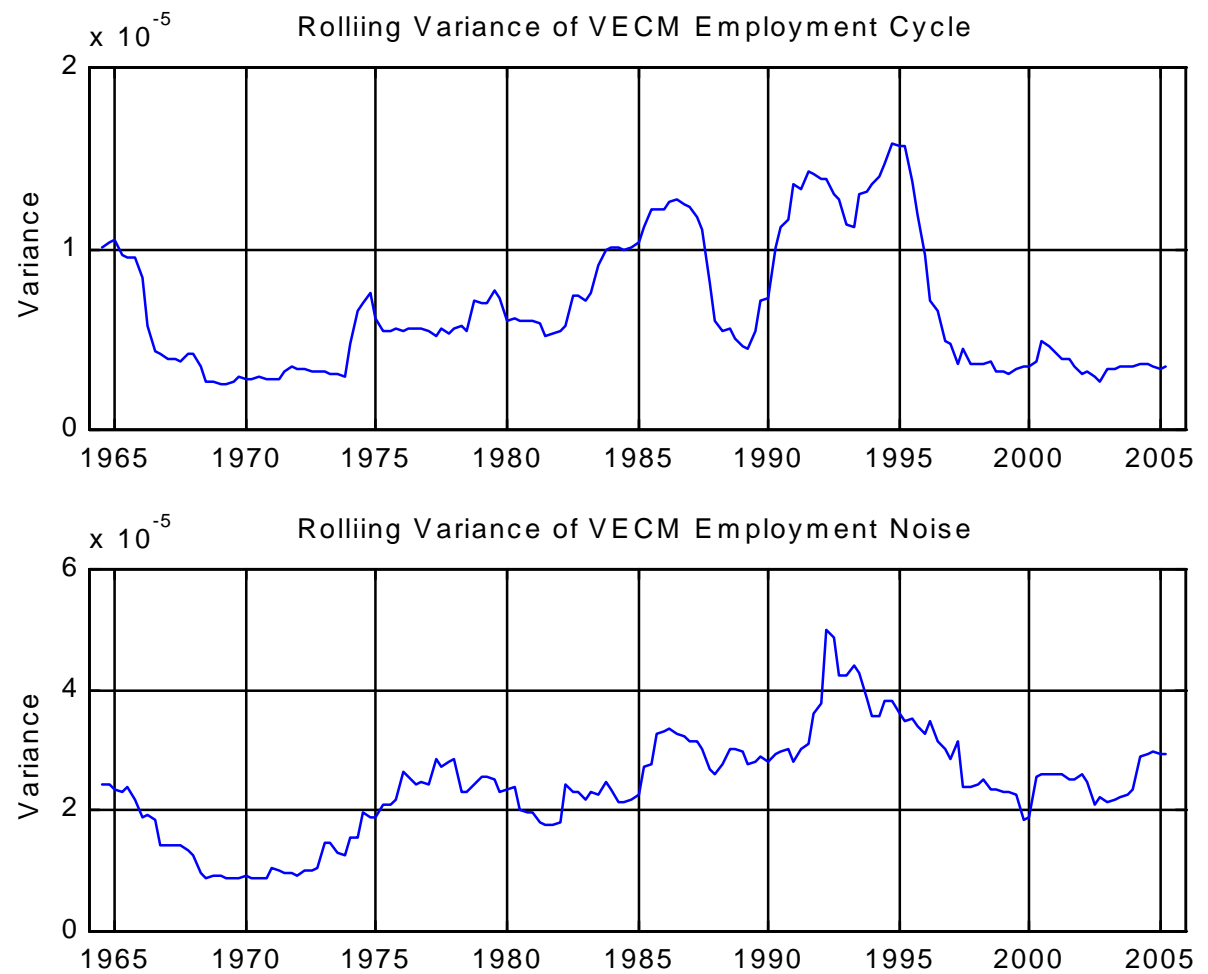

FIGURE 7

Power Spectral Densities: Output Growth, Employment Growth and White Noise 

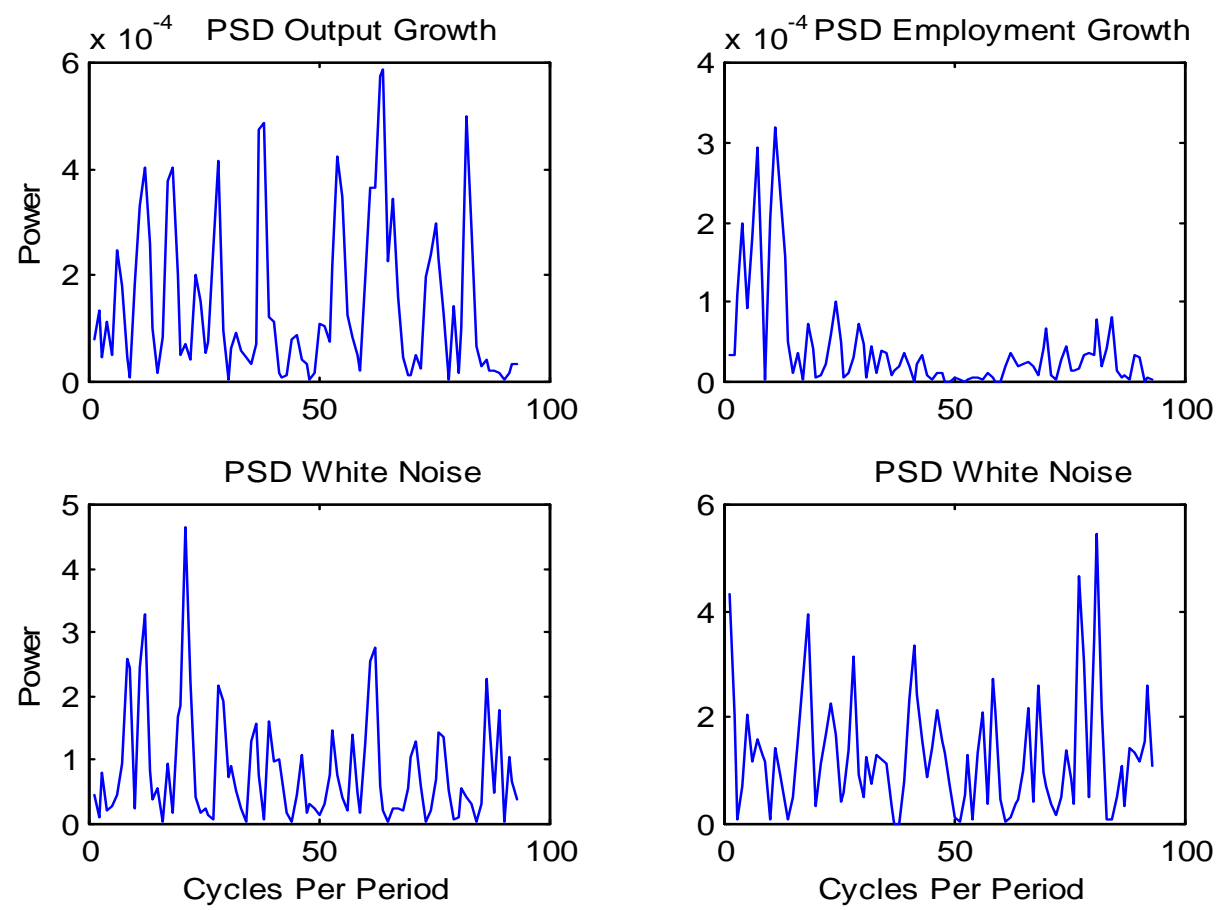
FIGURE 8

Detrended Output and Employment

Detrended G D P

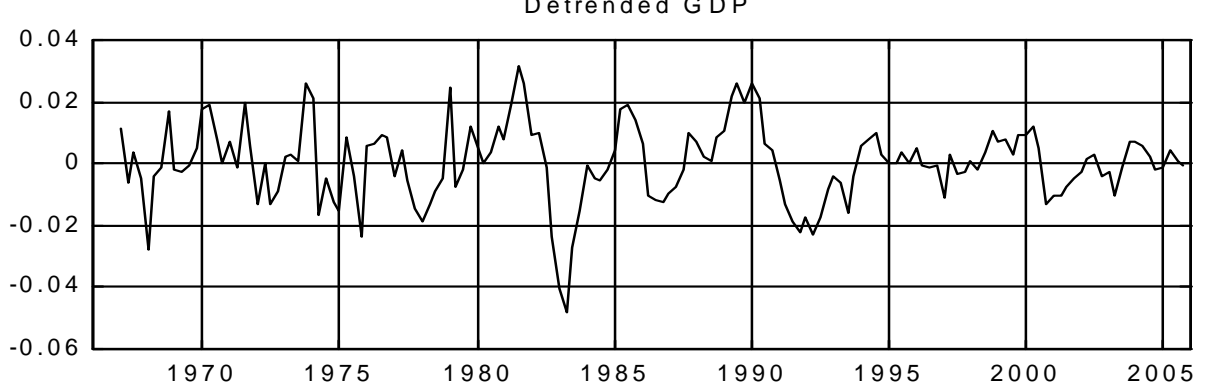

Detrended Em ploym ent

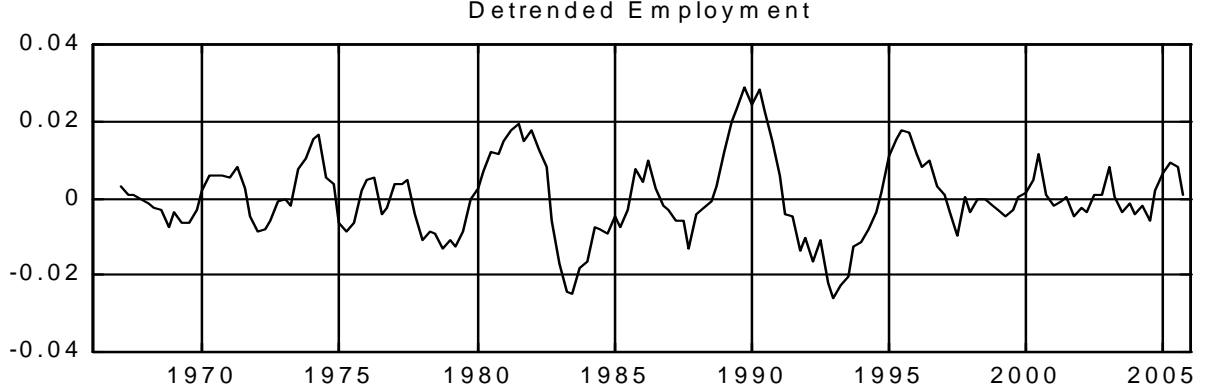

FIGURE 9

PSD of Detrended Output and Employment
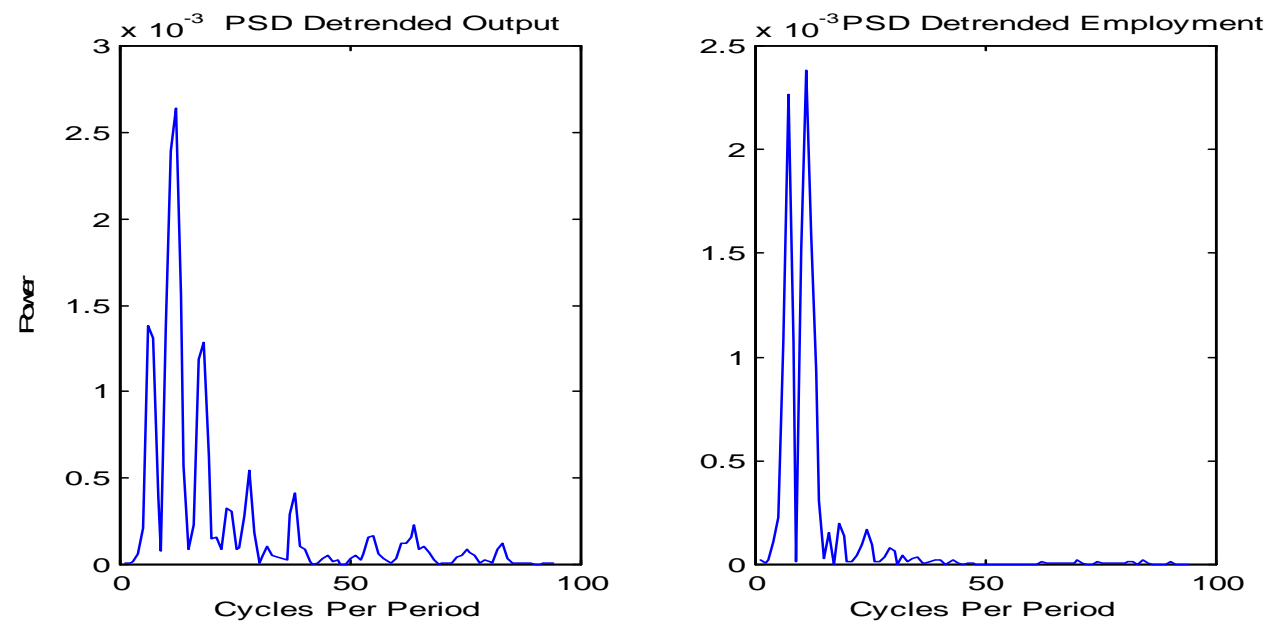
FIGURE 10

Filtered Cycles in Output and Employment
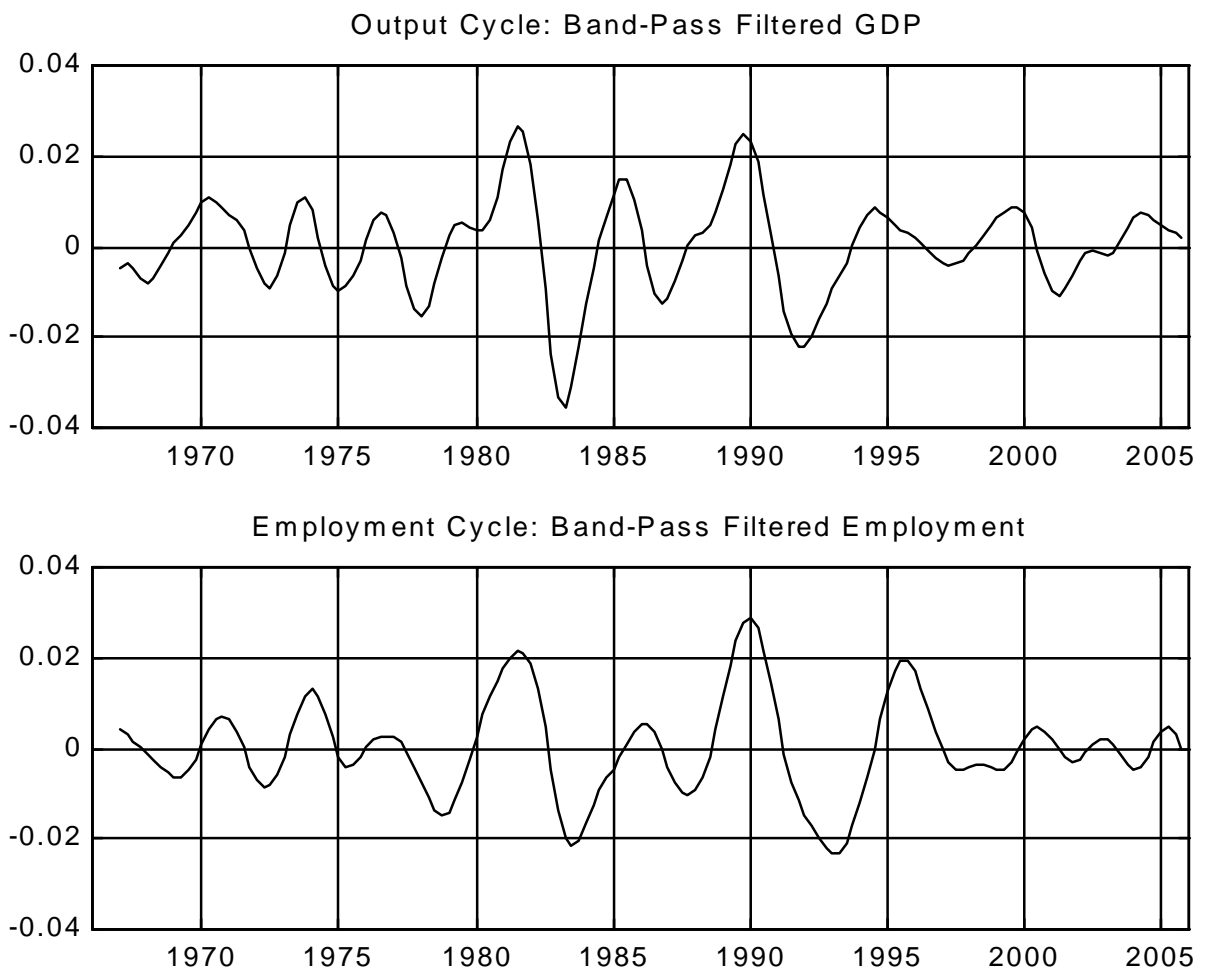
FIGURE 11

Filtered Noise Components of Output and Employment

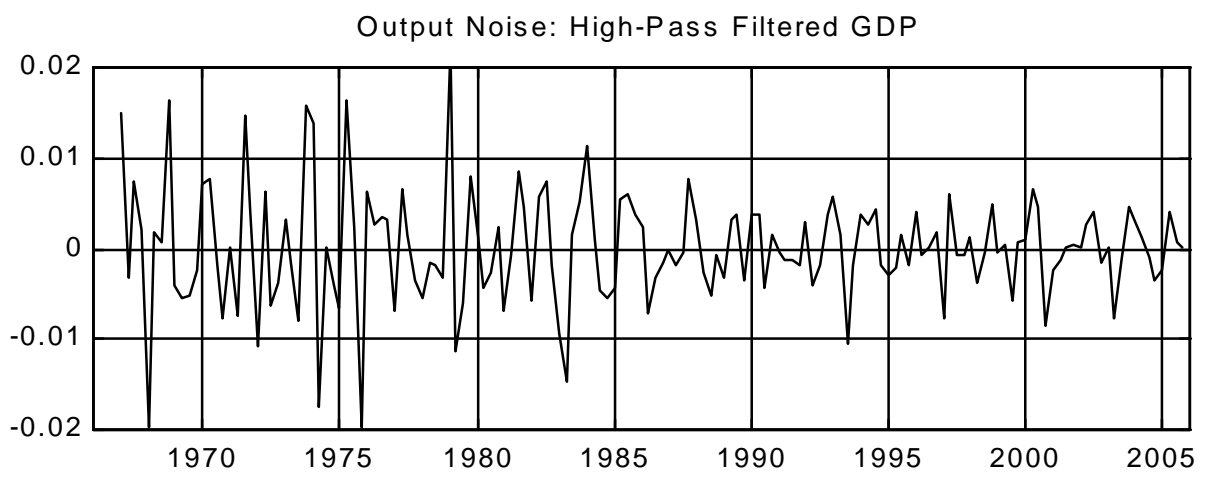

Employment Noise: High-Pass Filtered Employment

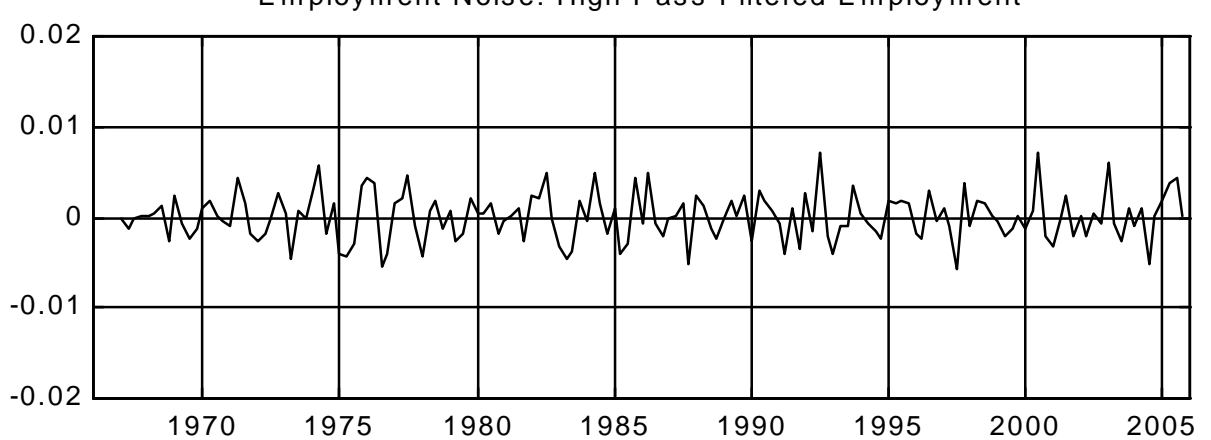


FIGURE 12

Rolling Variances of Filtered Output and Employment Cycles
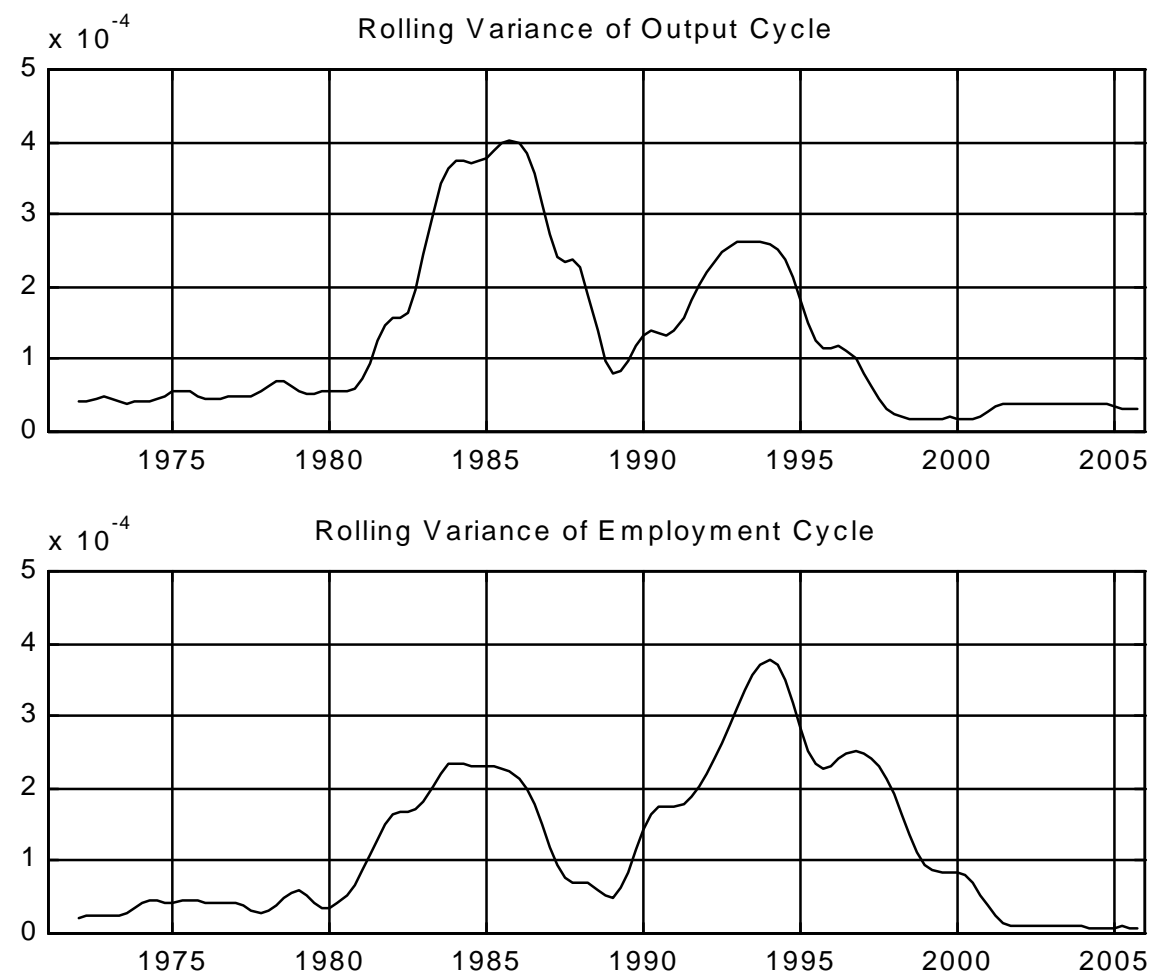
FIGURE 13

Rolling Variances of Filtered Output and Employment Noise
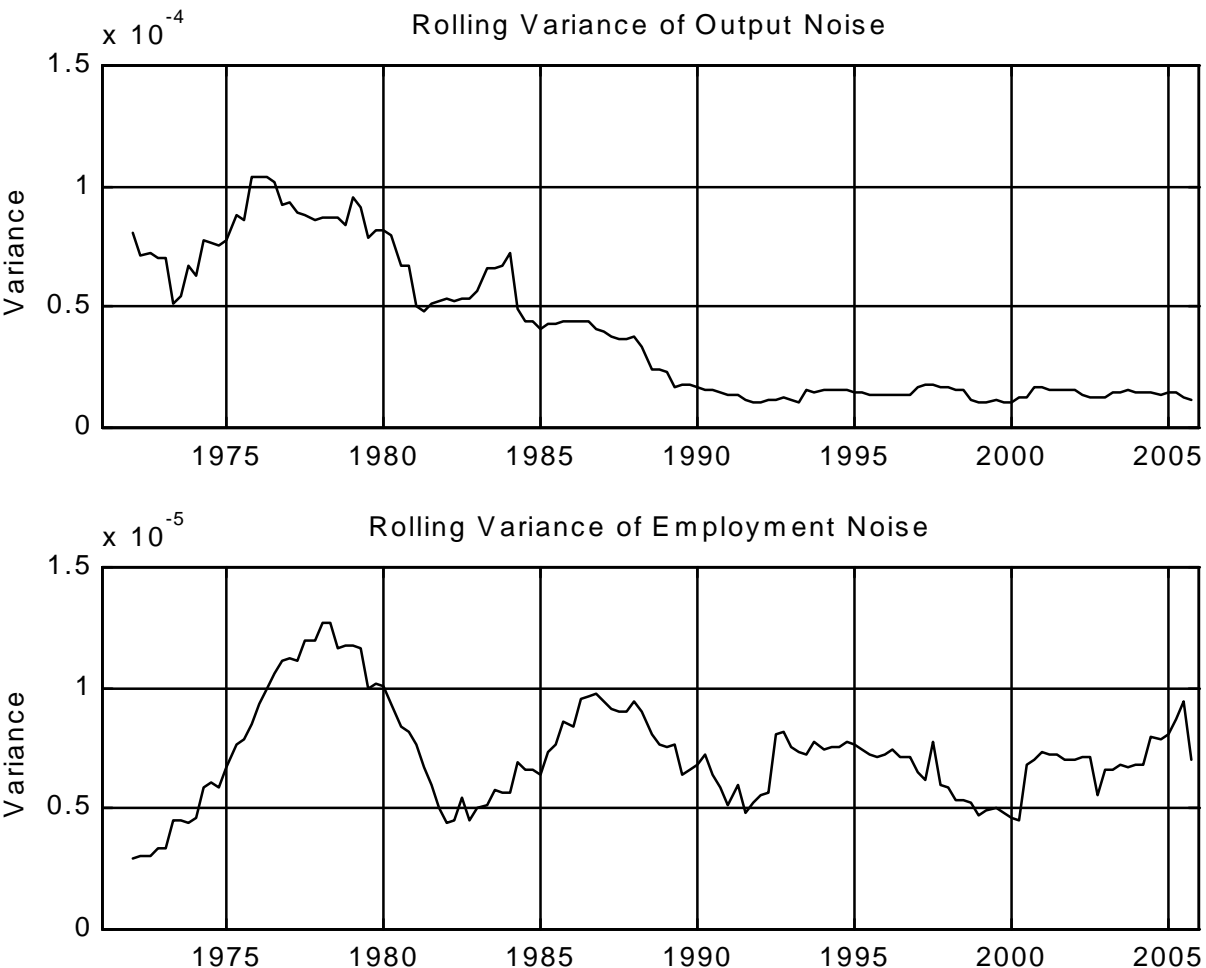

FIGURE 14

Output Growth and Trend Output Growth

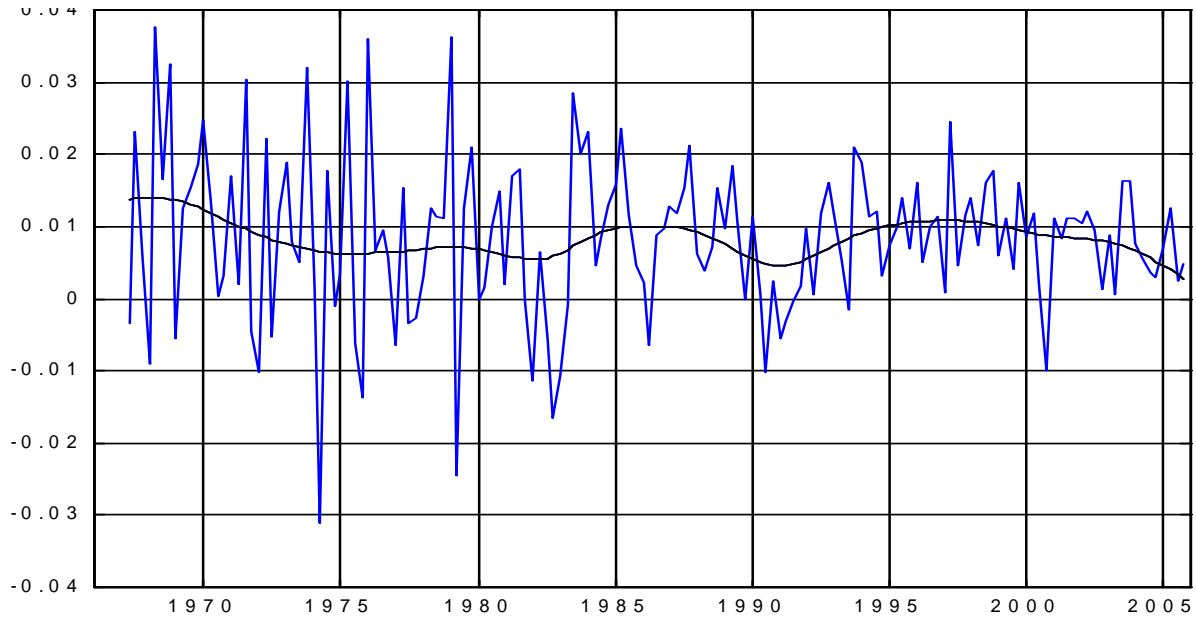


FIGURE A1

Rolling Variance plot of detrended output and employment
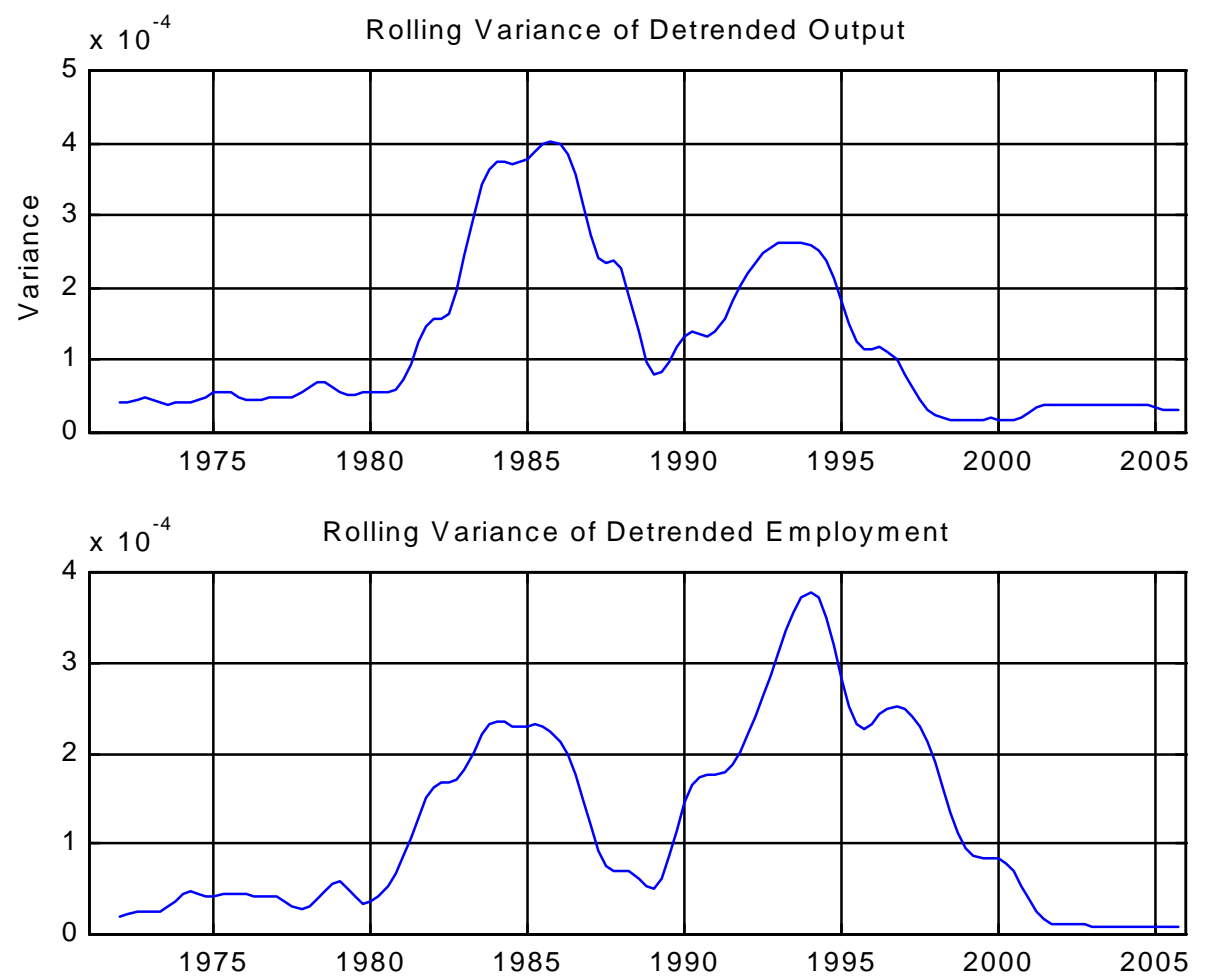
FIGURE A2

The cycle in detrended output (top) and the frequency filtered output cycle (bottom) $A R(1)$ Cycle in Detrended Output

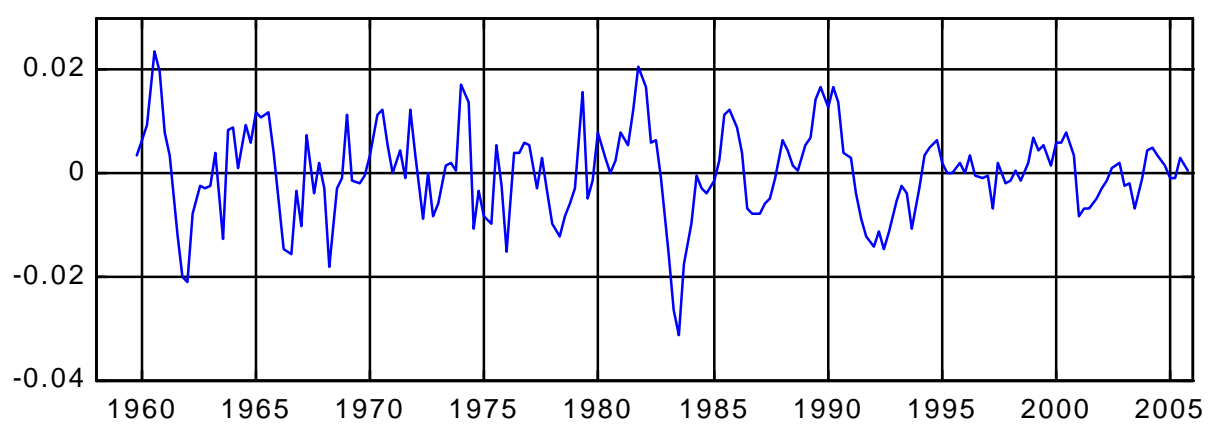

Band-Pass Filtered Output Cycle

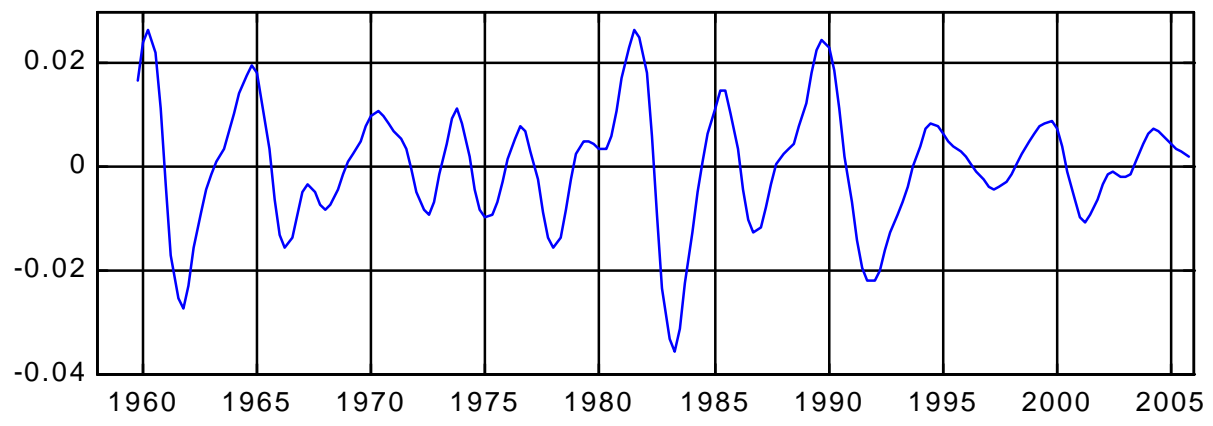


FIGURE A3

The cycle in detrended employment (top) and the frequency filtered employment cycle (bottom)

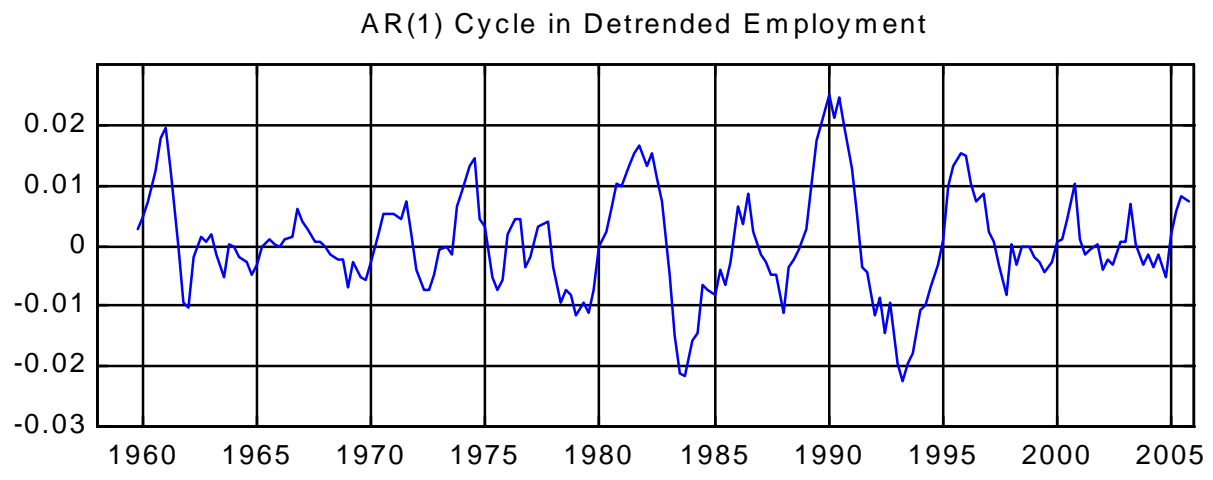

Band-Pass Filtered Employment Cycle

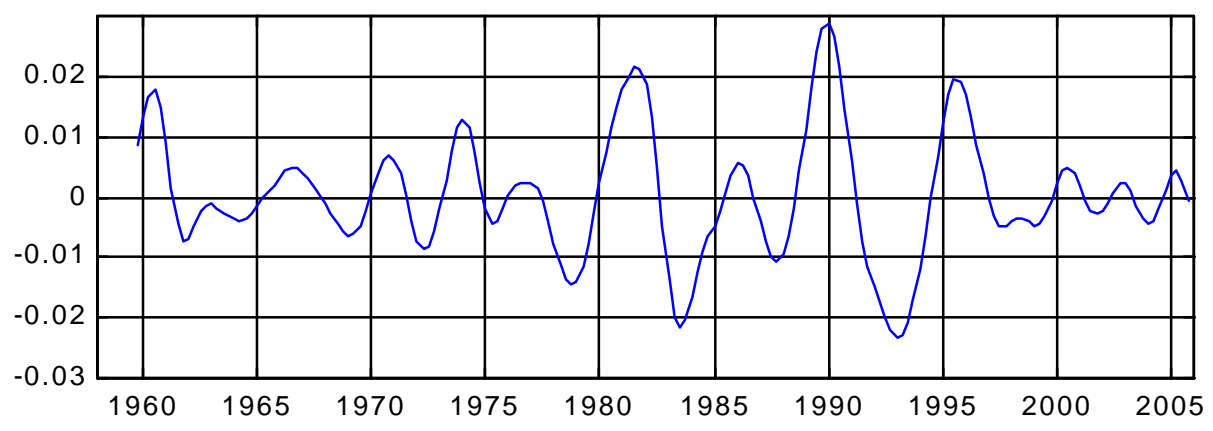


TABLES

TABLE 1

Correlation of $\Delta l_{t}$ with $\Delta y_{t}$

\begin{tabular}{|c|c|c|c|c|c|c|c|c|}
\hline$\Delta l_{\mathrm{t}-4}$ & $\Delta l_{\mathrm{t}-3}$ & $\Delta l_{\mathrm{t}-2}$ & $\Delta l_{\mathrm{t}-1}$ & $\Delta l_{\mathrm{t}}$ & $\Delta l_{\mathrm{t}+1}$ & $\Delta l_{\mathrm{t}+2}$ & $\Delta l_{\mathrm{t}+3}$ & $\Delta l_{\mathrm{t}+4}$ \\
\hline-0.05 & -0.08 & 0.04 & 0.18 & 0.26 & 0.29 & 0.22 & 0.19 & 0.12 \\
\hline
\end{tabular}

Correlation $5 \%$ significance level $=0.15$

TABLE 2

Correlation of Employment Cycle with Output Cycle: $l_{C t-i}$ and $y_{C t}$

\begin{tabular}{|c|c|c|c|c|c|c|c|c|}
\hline$l_{\mathrm{Ct}-4}$ & $l_{\mathrm{Ct}-3}$ & $l_{\mathrm{Ct}-2}$ & $l_{\mathrm{Ct}-1}$ & $l_{\mathrm{ct}}$ & $l_{\mathrm{Ct}+1}$ & $l_{\mathrm{Ct}+2}$ & $l_{\mathrm{Ct}+3}$ & $l_{\mathrm{Ct}+4}$ \\
\hline-0.23 & 0.01 & 0.25 & 0.49 & 0.67 & 0.78 & 0.81 & 0.75 & 0.61 \\
\hline
\end{tabular}

Correlation 5\% significance level $=0.15$ 
TABLE 3

Features of the Australian Output Cycle 1961:1 - 2003:2

\begin{tabular}{|c|c|c|c|c|c|c|c|}
\hline \multicolumn{4}{|c|}{ Contraction phases } & \multicolumn{4}{|c|}{ Expansion phases } \\
\hline Timing & Length & Amp & QAmp & Timing & Length & Amp & QAmp \\
\hline $\begin{array}{l}\text { 1961:1 - } \\
1963: 1\end{array}$ & 9 & -.1255 & -.0139 & & & & \\
\hline & & & & $\begin{array}{l}1963: 2- \\
1965: 3\end{array}$ & 10 & .0779 & .0078 \\
\hline $\begin{array}{l}1965: 4- \\
1968: 4\end{array}$ & 13 & -.0987 & -.0076 & & & & \\
\hline & & & & $\begin{array}{l}1969: 1- \\
1971: 3\end{array}$ & 11 & .0717 & .0065 \\
\hline $\begin{array}{l}1971: 4- \\
1973: 1\end{array}$ & 6 & -.0300 & -.0050 & & & & \\
\hline & & & & $\begin{array}{l}1973: 2- \\
1974: 2\end{array}$ & 5 & .0360 & .0072 \\
\hline $\begin{array}{l}1974: 3- \\
1975: 4\end{array}$ & 6 & -.0409 & -.0068 & & & & \\
\hline & & & & $\begin{array}{l}\text { 1976:1 - } \\
1977: 1\end{array}$ & 5 & .0253 & .0051 \\
\hline $\begin{array}{l}1977: 2- \\
1978: 4\end{array}$ & 7 & -.0644 & -.0092 & & & & \\
\hline & & & & $\begin{array}{l}\text { 1979:1 - } \\
1982: 2\end{array}$ & 14 & .1573 & .0112 \\
\hline $\begin{array}{l}\text { 1982:3 - } \\
1984: 2\end{array}$ & 8 & -.1727 & -.0216 & & & & \\
\hline & & & & $\begin{array}{l}\text { 1984:3 - } \\
1986: 1\end{array}$ & 7 & .0628 & .0090 \\
\hline $\begin{array}{l}1986: 2- \\
1987: 3\end{array}$ & 6 & -.0495 & -.0083 & & & & \\
\hline & & & & $\begin{array}{l}\text { 1987:4 - } \\
1990: 4\end{array}$ & 13 & .1522 & .0117 \\
\hline $\begin{array}{l}\text { 1991:1 - } \\
\text { 1993:3 }\end{array}$ & 11 & -.1519 & -.0138 & & & & \\
\hline & & & & $\begin{array}{l}1993: 4- \\
1996: 2 \\
\end{array}$ & 11 & .0491 & .0045 \\
\hline $\begin{array}{l}\text { 1996:3 - } \\
\text { 1998:1 }\end{array}$ & 7 & -.0193 & -.0028 & & & & \\
\hline & & & & $\begin{array}{l}\text { 1998:2 - } \\
2000: 2\end{array}$ & 9 & .0514 & .0057 \\
\hline $\begin{array}{l}2000: 3- \\
2003: 2\end{array}$ & 12 & -.0535 & -.0045 & & & & \\
\hline
\end{tabular}

"Length" is length of phase in quarters ; "Amp" is Amplitude, i.e. the cumulative value of the cyclical component for each phase and "QAmp" is the mean quarterly value of the cyclical component for that phase. 